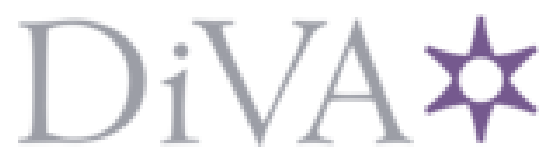

http://www.diva-portal.org

\title{
Preprint
}

This is the submitted version of a paper published in Carbohydrate Research.

Citation for the original published paper (version of record):

Widmalm, G. (2013)

A perspective on the primary and three-dimensional structures of carbohydrates.

Carbohydrate Research, 378: 123-132

http://dx.doi.org/10.1016/j.carres.2013.02.005

Access to the published version may require subscription.

N.B. When citing this work, cite the original published paper.

Permanent link to this version:

http://urn.kb.se/resolve?urn=urn:nbn:se:su:diva-94864 


\title{
Short Review
}

\section{A Perspective on the Primary and Three-dimensional Structures of Carbohydrates $^{\ddagger}$}

\section{Göran Widmalm}

Department of Organic Chemistry, Arrhenius Laboratory, Stockholm University, S-106 91 Stockholm, Sweden

E-mail: gw@organ.su.se

${ }^{\ddagger}$ Dedicated to the memories of Professor Lennart Kenne and Professor Malcolm Perry. Keywords: NMR spectroscopy, molecular dynamics, conformation, bacteria, lipopolysaccharide

\begin{abstract}
Carbohydrates, in more biologically oriented areas referred to as glycans, constitute one of the four groups of biomolecules. The glycans, often present as glycoproteins or glycolipids, form highly complex structures. In mammals ten monosaccharides are utilized in building glycoconjugates in the form of oligo- (up to about a dozen monomers) and polysaccharides. Subsequent modifications and additions create a large number of different compounds. In bacteria, more than a hundred monosaccharides have been reported to be constituents of lipopolysaccharides, capsular polysaccharides, and exopolysaccharides. Thus, the number of polysaccharide structures possible to create is huge. NMR spectroscopy plays an essential part in elucidating the primary structure, i.e., monosaccharide identity and ring size, anomeric configuration, linkage position, and sequence, of the sugar residues. The structural studies may also employ computational approaches for NMR chemical shift predictions (CASPER program).
\end{abstract}

Once the components and sequence of sugar residues have been unraveled, the threedimensional arrangement of the sugar residues relative to each other (conformation), their flexibility (transitions between and populations of conformational states), together with the dynamics (timescales) should be addressed. To shed light on these aspects we have utilized a combination of experimental liquid state NMR techniques together with molecular dynamics simulations. For the latter a molecular mechanics force field such as our CHARMM-based PARM22/SU01 has been used. The experimental NMR parameters acquired are typically ${ }^{1} \mathrm{H},{ }^{1} \mathrm{H}$ cross-relaxation rates (related to NOEs), ${ }^{3} J_{\mathrm{CH}}$ and ${ }^{3} J_{\mathrm{CC}}$ trans-glycosidic coupling constants and ${ }^{1} \mathrm{H},{ }^{13} \mathrm{C}$ - and ${ }^{1} \mathrm{H},{ }^{1} \mathrm{H}$-residual dipolar couplings. At a glycosidic linkage two torsion angles $\phi$ and $\psi$ are defined and for 6 -substituted residues also the $\omega$ torsion angle is required. Major conformers can be identified for which highly populated states are present. Thus, in 
many cases a well-defined albeit not rigid structure can be identified. However, on longer timescales, oligosaccharides must be considered as highly flexible molecules since also anti-conformations have been shown to exist with $\mathrm{H}-\mathrm{C}-\mathrm{O}-\mathrm{C}$ torsion angles of $\sim 180^{\circ}$, compared to syn-conformations in which the protons at the carbon atoms forming the glycosidic linkage are in close proximity.

The accessible conformational space governs possible interactions with proteins and both minor changes and significant alterations occur for the oligosaccharides in these interaction processes. Transferred NOE NMR experiments give information on the conformation of the glycan ligand when bound to the proteins whereas saturation transfer difference NMR experiments report on the carbohydrate part in contact with the protein. It is anticipated that the subtle differences in conformational preferences for glycan structures facilitate a means to regulate biochemical processes in different environments. Further developments in analysis of glycan structure and in particular its role in interactions with other molecules, will lead to clarifications of the importance of structure in biochemical regulation processes essential to health and disease.

\section{Introduction}

Among biopolymers those based on monosaccharides include, inter alia, starch and cellulose, $\alpha$ - and $\beta$ $(1 \rightarrow 4)$-linked D-glucans, respectively and chitin which is a polymer of $\beta$-( $1 \rightarrow 4)$-linked $N$-acetyl-Dglucosamine residues. The structural complexity is increased in polymers like heparin in which a large number of sulfate substituents are present. In bacterial polysaccharides the number of monosaccharides that may be a constituent is increased by more than one order of magnitude compared to those in mammals. In addition, the cell wall of the bacteria often contains polysaccharides (Figure 1). ${ }^{1}$ These polysaccharides may have one or more branches, in contrast to proteins and nucleic acids that are linear polymers, as part of the repeating unit. ${ }^{2,3}$ The latter refers to the oligosaccharide block used in the biosynthesis and typically it contains up to seven sugar residues per repeat. In a lipopolysaccharide (LPS), schematically shown in Figure 2, the polysaccharide part can be presented in a couple of ways and the choice may seem random when only a handful of structures are studied. From a larger collection of polysaccharides it was possible to find a consistent systematic biosynthesis scheme producing the LPS, such as for Escherichia coli ${ }^{4}$ which contains an $N$-acetyl-D-glucosamine or an $N$ acetyl-D-galactosamine residue at the reducing end of the biological repeating unit (when the Wzx/Wzy-dependent biosynthetic pathway is utilized). Thus, knowledge of biosynthesis is helpful in carrying out structural studies of these molecules. In determining the primary structure of a polysaccharide one has to address the following: sugar components and substituents, ring size and 
anomeric configuration of the sugar residues, and in particular sequence order of the constituent monosaccharides.

For $N$ - and $O$-linked glycans $s^{5,6,7}$ a large amount of knowledge is available for the highly conserved biosynthetic pathways and to a large extent profiling alterations in the glycome, i.e., an organism's complete repertoire of glycans, ${ }^{8}$ of e.g. mammals is rapidly carried out using mass spectrometry (MS) techniques. However, novel monosaccharides, ${ }^{9,10}$ glycolipids of biochemical interest, $^{11}$ structural features ${ }^{12}$ and modifications do occur for these glycoconjugates and therefore NMR spectroscopy is still the method of choice for determining the anomeric configurations of sugar

residues, ${ }^{13}$ although developments aimed at solving this problem by MS are being pursued. ${ }^{14}$ It is, however, the three-dimensional (3D) structure including charge, hydrogen bonding and hydrophobic interactions as well as flexibility that is of importance in resolving the way in which a molecule function and interacts with other molecules. We have utilized X-ray crystallography, solid ${ }^{15}$ and solution state NMR spectroscopy and a number of different molecular simulation ${ }^{16}$ approaches to address 3D structure.

\section{Primary structure determination}

During the first half of the 1980s the use of 2D NMR spectroscopy entered the area of structure determination and the arsenal of specific chemical degradations was exchanged with an array of experiments that supplied data on through-bond ${ }^{17,18}$ and through space ${ }^{19}$ NMR correlations. As a result the amount of material needed to carry out a structural determination of e.g. a bacterial polysaccharide was decreased by more than one order of magnitude. Preparation of material suitable for NMR structural analysis, in particular homogenous as well as not too viscous for solution state NMR spectroscopy, is still a bottle-neck since several physico-chemical separation techniques may be necessary to this end and for LPS they have usually been analyzed as the PS, the lipid part removed by a mild acid treatment. However, this may lead to unwanted modifications as well as breakdown and other approaches are needed to resolve these problems. It is sometimes possible to analyze the polysaccharide part of the intact LPS. ${ }^{20}$ This was carried out in the studies of the E. coli O124 and S. dysenteriae type 3 LPS. $^{21}$

Under alkaline conditions the LPS loses its ester-linked fatty acids and the resulting LPS-OH is often useful for structure studies. The resulting NMR spectrum may then be of sufficiently high quality for structural determination of the O-antigen polysaccharide, as exemplified by the ${ }^{1} \mathrm{H},{ }^{13} \mathrm{C}-\mathrm{HSQC}$ NMR spectrum of the LPS-OH from E. coli O112ab (Figure 3), one of two E. coli O112 serogroups, the other being E. coli O112ac. ${ }^{22,23}$ This approach was successfully used in the structural studies of the O-antigen 
from E. coli O171, which contains an acid-labile sialic acid residue as part of the repeating unit. ${ }^{24}$ Determination of the 'biological repeating unit' of the polysaccharide, i.e., the oligosaccharide used by the polymerases, by NMR spectroscopy has been feasible in several cases. The identification of additional sets of NMR resonances of low intensity emanating from the terminal residues in the polymer made this possible. ${ }^{25,26}$ Apart from having a different substitution pattern they also show more rapid dynamics. $^{27}$ One example is shown in Figure 4, from the polysaccharide of the verotoxin producing E. coli O176, ${ }^{28}$ where the cross-peaks of low intensity in a ${ }^{1} \mathrm{H},{ }^{1} \mathrm{H}$-TOCSY spectrum were fully consistent with an $\alpha$-D-Manp-(1 $\rightarrow 2)-\alpha-\mathrm{D}-\mathrm{Manp}-(1 \rightarrow$ structural element terminating the polysaccharide. At the reducing end of the repeating unit an $N$-acetyl-D-galactosamine residue was present in complete agreement with the concept of a 'biological repeating unit'.

At about the same time as the 2D NMR techniques entered the field a development for structural analysis of polysaccharides based on ${ }^{13} \mathrm{C}$ chemical shift predictions was initiated and by December 1983 the first version of what would be known as the computer program CASPER (Computer Assisted SPectrum Evaluation of Regular polysaccharides) programmed in SIMULA was able to determine the structure of pullulan, a D-glucan homopolymer having $\alpha-(1 \rightarrow 4)$ - and $\alpha-(1 \rightarrow 6)$ linkages, based on a $1 \mathrm{D}{ }^{13} \mathrm{C}$ NMR spectrum. The approach was presented at the XIIIth International Carbohydrate Symposium, August 1986, Ithaca, NY, USA, and published in the subsequent year. ${ }^{29}$ Continued developments including branched structures and oligosaccharides, ${ }^{1} \mathrm{H}$ and $2 \mathrm{D}$ NMR data ${ }^{30,31}$ as well as being accessible via the internet (www.casper.organ.su.se) ${ }^{32}$ has made it a useful tool. Not only for structural determination of polysaccharides but even more so for the prediction of ${ }^{1} \mathrm{H}$ and ${ }^{13} \mathrm{C}$ NMR chemical shifts of synthetic oligosaccharides and as an NMR assignment aid in studies in which reliable chemical shift estimates are valuable in order to analyze a complex molecule. For a structural determination, the component monosaccharides including data on the absolute configuration were originally needed as input to CASPER, in addition to the NMR data. The principal advantage of CASPER is that it is able to rapidly propose a highly probable structure from unassigned NMR spectra. If additional structural confirmation is needed it can readily be obtained by carrying out a selected experiment, typically by NMR, that differentiates the top-ranked structures. This approach was used in the structural determination of the O-antigen polysaccharide from E. coli O18ac. ${ }^{33}$ The future interplay between CASPER and 2D and $3 \mathrm{D}$ NMR techniques ${ }^{34}$ including ${ }^{13} \mathrm{C}$ and/or ${ }^{15} \mathrm{~N}$ isotope enrichment ${ }^{35,36,37,38}$ in structural analysis of complex glycans promises interesting developments for rapid NMR resonance assignments with highly automatic, ${ }^{39}$ less user intervened, and more time-saving procedures, i.e., the manual NMR assignment process will be further reduced. 


\section{Conformational analysis}

The conformational analysis of glycans is comprised of three areas: monosaccharides, oligosaccharides and polysaccharides. Whereas sugar ring flexibility is important in cases such as furanosides, ${ }^{40}$ e.g., in DNA, RNA, the disaccharide sucrose, ${ }^{41}$ and the hexopyranose $\alpha$-L-IdopA ${ }^{42}$ (the C5 epimer of $\beta$-DGlcpA) present in heparin, many hexopyranoses ${ }^{43}$ can be regarded as relatively rigid entities. For polysaccharides, on the other hand, complex polymer dynamics ${ }^{27,44}$ have to be addressed giving rise to additional complexity, besides that of glycosidic conformation, flexibility and dynamics. Herein we limit the description to oligosaccharides having hexopyranoid residues.

For a glycosidic linkage, i.e., the two bonds that connect two sugar residues, there are two torsion angles $\phi$ (H1'-C1'-On-Cn where $\mathrm{n}$ is the substitution position) and $\psi(\mathrm{C} 1$ '-On-Cn-Hn) when substitution occurs on a secondary ring carbon as in $\beta$-L-Fucp-( $1 \rightarrow 2)$ - $\alpha$-D-Glcp-OMe (Figure $5 \mathrm{a}$ ). ${ }^{45}$ In a $(1 \rightarrow 6)$-linkage there is an additional torsion angle $\omega(\mathrm{O} 5-\mathrm{C} 5-\mathrm{C} 6-\mathrm{O} 6)$ that has to be considered; an example is $\quad(R)-1$-cyano-1-(phenylmethyl)- $\beta$-D-glucopyranosyl-( $1 \rightarrow 6)-\beta$-D-glucopyranoside, $\quad$ or amygdalin (Figure 5b). ${ }^{46}$ Before addressing the conformational preferences at the $\phi$ and $\psi$ torsion angles we consider the flexibility at the $\omega$ torsion angle. Assuming that staggered conformers or librations close to the potential energy minima give an appropriate description of the possible conformational equilibrium three conformations are considered and these are denoted using carbohydrate nomenclature as gauche-trans (gt) with $\omega=60^{\circ}$, gauche-gauche (gg) with $\omega=-60^{\circ}$, and trans-gauche $(\mathrm{tg})$ with $\omega=180^{\circ}$, where the first letter describes the relationship of C6-O6 to C5-O5 and the second relates C6-O6 to C5-C4; thus, historically two letters have been used to describe one torsion angle. NMR coupling constants are very powerful parameters to determine conformation and conformational equilibria. ${ }^{47}$ Knowledge of each of the ${ }^{3} J_{\mathrm{H} 5, \mathrm{H} 6 \mathrm{pro}-R}$ and ${ }^{3} J_{\mathrm{H} 5 \text {,H6pro-S coupling constants for }}$ the three staggered conformers then facilitates the determination of a conformational equilibrium since an additional restraint can be formulated, viz., the sum of the three populations is equal to unity. However, some of the Karplus-type relationships led to 'negative populations', ${ }^{48}$ clearly an unphysical

state. To obtain appropriate ${ }^{3} J_{\mathrm{H} 5, \mathrm{H} 6}$ coupling constants the monosaccharides glucose and galactose can be derivatized by a 4,6-acetal group thereby fully restricting the conformation for the $\omega$ torsion angle to the $\operatorname{tg}$ and $g g$ conformations, respectively (Figure 6). Unfortunately, there was no suitable monosaccharide model for the gt conformation (Figure 6). A nine-atom cyclic derivative had been made, ${ }^{49}$ but this did not result in a model compound in which the torsional restraint could be judged appropriately restricted. The problem was solved during the mid-1990s when a model compound was 
proposed to appropriately represent the gt conformation, viz., trans-2,5-bis(hydroxymethyl)-1,4dioxane (Figure 6). The coupling constants corresponding to ${ }^{3} J_{\mathrm{H} 5 \text {,H6pro- } R}$ and ${ }^{3} J_{\mathrm{H} 5 \text {,H6pro-S }}$ were determined and a novel set of Karplus-type relationships for the torsion angle $\omega$ in hexopyranoses ${ }^{50}$ is subsequently in use to address conformational aspects. To a first approximation the conformational equilibrium in glucopyranose is approximately 1:1 for the $g t: g g$ conformations whereas in galactopyranose the relative ratio is approximately 3:1 for the gt:tg conformations. The conformations in which there is a 1,3electronegative interaction are avoided, also referred to as the Hassel-Ottar effect, ${ }^{51}$ and are only populated to a limited extent.

We now turn to the torsion angles $\phi$ and $\psi$ relating the orientation of the sugar residues relative to each other. It is now well recognized that the torsion angle $\phi$ at the glycosidic linkage populates to a large extent a conformation referred to as an exo-anomeric conformation ${ }^{52}$ (being of the same origin as the anomeric effect ${ }^{53,54,55}$ ). This results in $\phi \approx+40^{\circ}$ in $\beta$-D- or $\alpha$-L-hexopyranosides and $\phi \approx-40^{\circ}$ in $\alpha$ D- or $\beta$-L-hexopyranosides. The $\psi$ torsion angle is anticipated to be in the range $+50^{\circ}$ to $-50^{\circ}$. A strong ${ }^{1} \mathrm{H},{ }^{1} \mathrm{H}$ NOE between $\mathrm{H} 1$ ' and $\mathrm{Hn}$, where $\mathrm{n}$ is the substitution position (H2 in Figure 5a), is usually present and shows that this 'syn-conformation', where H1' and $\mathrm{Hn}$ are on the same side of the plane perpendicular to the $\mathrm{C} 1$ '-H1' vector, is a major conformation populated to a large extent.

From Ramachandran maps it could be anticipated that anti-conformers, i.e., $\phi$ or $\psi \approx 180^{\circ}$, could be populated to some extent. ${ }^{56}$ Whether they could be confirmed experimentally was an open question at the time. By the mid-1990s Dabrowski and co-workers used NMR spectroscopy to present reliable evidence, using a deuterium isotope effect, for the presence of an anti- $\psi$ conformer in a $\beta$ $(1 \rightarrow 3)$-linked disaccharide ${ }^{57}$ in DMSO solution. Shortly thereafter we were able to show by NMR that also an anti- $\phi$ conformation was populated in a trisaccharide. ${ }^{58}$ In the latter case the molecular mechanics force field approach used initially indicated that the conformational space was highly restricted. ${ }^{59}$ However, it was instead highly flexible and further studies of the trisaccharide showed that both anti- $\phi$ and anti- $\psi$ conformational states were populated as determined by NMR spectroscopy and interpreted using molecular dynamics (MD) simulations. ${ }^{60}$

In conformational analysis of oligosaccharides ${ }^{1} \mathrm{H},{ }^{1} \mathrm{H}$ NOEs play an important role but the ${ }^{1} \mathrm{H},{ }^{1} \mathrm{H}$ cross-relaxation rates are related to the distance by an $<r^{-6}>$-relationship thereby making the interpretation difficult. In addition, cross-relaxation via an intervening spin, also known as a three-spin effect, may lead to erroneous interpretations. A remedy for this is to 'remove' it from the spin system under study using selective irradiation as in the MINSY-experiment ${ }^{61}$ or by other irradiation schemes, ${ }^{62}$ which are highly useful when the resonance can be targeted by selective pulses. Another way to 
decimate the contribution from a third proton to the desired interaction is to chemically exchange ${ }^{1} \mathrm{H}$ for ${ }^{2} \mathrm{H}$ atoms, which effectively eliminates contributions via the undesired relaxation pathway. ${ }^{63,64}$ Thus, if spectral appearance permits selective irradiation, it is the method of choice, otherwise a chemical substitution approach is needed. A full relaxation matrix approach is also feasible to apply to address possible spin-diffusion effects. ${ }^{65,66}$

In our analysis of the conformational flexibility of methyl cellobioside the spectral overlap precluded a selective irradiation approach and a site-specifically ${ }^{2} \mathrm{H}$-labeled disaccharide was synthesized. The ${ }^{2} \mathrm{H}$-labeling was required at $\mathrm{C} 4$ of the reducing end sugar in order to measure ${ }^{1} \mathrm{H},{ }^{1} \mathrm{H}$ NOEs between the anomeric proton $\mathrm{H} 1$ ' and protons other that $\mathrm{H} 4$. To introduce a ${ }^{2} \mathrm{H}$ atom at $\mathrm{C} 4$ of a hexose derivative, reduction with $\mathrm{NaB}^{2} \mathrm{H}_{4}$ of a suitably protected 4-keto derivative seemed a straightforward approach. However, a 9:1 mixture was obtained, dominated by of the undesired galactose derivative. The problem was solved by an intra-molecular delivery using the hydroxymethyl group as a carrier of the reducing agent. $\mathrm{NaB}^{2} \mathrm{H}(\mathrm{OAc})_{3}$ was used to form the intermediate attached to O6 and subsequent intramolecular reduction took place in a highly stereoselective way (Figure 7). The sole product isolated in $84 \%$ yield had the gluco-configuration and the extent of deuteration was $>98 \% .{ }^{67}$ As part of the synthesis the easily handled solid reagent 1,3-dibromo-5,5-dimethylhydantoin was used and subsequently shown to be a suitable reagent to oxidize secondary hydroxyl groups to ketones. ${ }^{68}$ The glycosylation reaction was carried out using well established methodology ${ }^{69}$ and gave, after deprotection the site-specifically ${ }^{2} \mathrm{H}$-labeled methyl cellobioside. The NMR experiment of choice was the $1 \mathrm{D}{ }^{1} \mathrm{H},{ }^{1} \mathrm{H}$ T-ROESY experiment ${ }^{70}$ which is highly sensitive for small oligosaccharides in contrast to the ${ }^{1} \mathrm{H},{ }^{1} \mathrm{H}$ NOE experiment since zero-crossing at $\omega \tau_{\mathrm{c}}=1.12$ leads to absence of an NOE for this combination of the spectrometer frequency $\omega$ and the molecular correlation time $\tau_{c}$. It was now possible to show that, in addition to syn-conformations, both anti- $\phi$ and anti- $\psi$ conformational states were present to a few percent at the glycosidic linkage of methyl cellobioside. ${ }^{71}$ Initially, it was anticipated that either of the H1'-H3 or H1'-H5 interactions could be used to assess the degree of anti$\psi$ conformations populated in the disaccharide. The MD simulation of the disaccharide started from the anti- $\psi$ conformation revealed, however, that to assess the degree of anti- $\psi$ states only the H1'-H3 interaction should be analyzed in the approach taken. Thus, oligosaccharides must be regarded as potentially highly flexible molecules in which different entities can have different degrees of flexibility. Additional studies on flexibility and dynamics carried out for various oligosaccharides have confirmed these findings. ${ }^{72,73}$ 
Analysis of oligosaccharide conformation and in particular of glycosidic torsion angles based on NMR techniques related to the NOE are limited since most often only a single strong NOE is present across the glycosidic linkage. Additional restraints are then needed, such as trans-glycosidic ${ }^{3} J$ coupling constants ${ }^{74}$ or residual dipolar couplings (RDCs). ${ }^{75}$ The heteronuclear ${ }^{3} J_{\mathrm{CH}}$ coupling constants presents useful information and can be extracted from 1D Hadamard ${ }^{76}$ or $2 \mathrm{D}$ NMR experiments. The advantage with the 1D Hadamard encoded experiment is that very good signal-to-noise ratios can be obtained. The ${ }^{3} J_{\mathrm{CH}}$ coupling constants in the latter case are usually extracted using a fitting procedure in which a series of trial coupling constants are tested and the experimental ${ }^{3} J_{\mathrm{CH}}$ value is determined when the optimum fit is obtained. In the two-dimensional case we have made use of the J-HMBC experiment ${ }^{77}$ in which ${ }^{3} J_{\mathrm{CH}}$ values related to $\phi$ and $\psi$ can be extracted from a single 2D experiment. An advantage is that the spectral appearance can be changed via the alteration of a scaling factor $\kappa$ and consequently spectral overlap can be eliminated. 1D slices from the 2D J-HMBC spectrum related to $\phi$ and $\psi$ for a disaccharide are shown in Figure 8. In an oligosaccharide from $M$. catarrhalis $^{78}$ the large value of one of the ${ }^{3} J_{\mathrm{CH}}$ coupling constants related to a $\psi$ torsion angle indicated an altered conformation, $^{79}$ i.e., an anti- $\psi$ conformation. This result is consistent with our analysis of related oligosaccharides which showed that a significant conformational change did occur when the oligosaccharide was of sufficient size, i.e., when a branched oligosaccharide was extended by additional sugar residues. Thus, pronounced ${ }^{1} \mathrm{H},{ }^{1} \mathrm{H}$ NOEs were observed to H3 of the branch-point $\alpha$ D-Glcp residue (A) from the anomeric protons of the $\beta$-D-Glcp-(1 $\rightarrow 3)$ - and $\beta$-D-Glcp-(1 $\rightarrow 4)$-linked residues (B and $\mathbf{C}$, respectively) being constituents of the oligosaccharide (Figure 9). The analysis revealed that a conformational carbohydrate scaffold ${ }^{80}$ was formed having a characteristic 3D structure for the short-chain LPS of Moraxella catarrhalis.

The information gathered from the trans-glycosidic ${ }^{3} J_{\mathrm{CH}}$ coupling constants may be complemented by ${ }^{3} J_{\mathrm{C}, \mathrm{C}}$ which are readily determined from a $1 \mathrm{D}{ }^{13} \mathrm{C}$ NMR spectrum when site-specific ${ }^{13} \mathrm{C}$-labeling has been carried out. ${ }^{81}$ As for the ${ }^{3} J_{\mathrm{CH}}$ trans-glycosidic heteronuclear coupling constants those between ${ }^{13} \mathrm{C}$-nuclei can be interpreted via Karplus-type relationships ${ }^{82}$ giving information on populated conformational states. Furthermore, site-specific ${ }^{13} \mathrm{C}$-labeling is particularly important in that it can resolve ${ }^{1} \mathrm{H}$ spectral overlap (Figure 10) due to the large ${ }^{1} J_{\mathrm{CH}}$ coupling constant $(145-175 \mathrm{~Hz}$ ). As a result the ${ }^{1} \mathrm{H}$ spectral appearance changes and can be chosen by selecting a suitable ${ }^{1} \mathrm{H}$ resonance frequency (not necessarily the highest magnetic field) since ${ }^{1} J_{\mathrm{CH}}$ is constant. ${ }^{1} \mathrm{H},{ }^{1} \mathrm{H}-\mathrm{NOE}$ studies can subsequently be carried out which previously were intractable with natural abundance material. To determine pico- to nanosecond dynamics it is possible by utilize ${ }^{13} \mathrm{C}$ auto-relaxation studies commonly 
carried out at several magnetic fields and interpreted using the model-free formalism devised by Lipari and Szabo. ${ }^{83}$ We have determined motional properties of several oligosaccharides using this procedure. ${ }^{72,84,85}$ The ${ }^{13} \mathrm{C}$ NMR spin-relaxation methodology has been described in more detail in a book chapter ${ }^{86}$ and will not be covered herein.

In addition to the three experimental NMR approaches mentioned above, viz., ${ }^{1} \mathrm{H},{ }^{1} \mathrm{H}-\mathrm{NOE},{ }^{3} J$ coupling constants and ${ }^{13} \mathrm{C}$ auto-relaxation data we have found a fourth approach highly suitable for conformational and dynamics studies of oligosaccharides, i.e., RDCs. The nuclear dipole-dipole interaction (giving rise to NOEs) is averaged to zero in an isotropic solution but can be recovered by use of an anisotropic lyotropic liquid crystal medium. ${ }^{75}$ This has been known for a long time and was described in detail in the 1960s. ${ }^{87}$ In high-resolution NMR their use was set off by the application to proteins and nucleic acids and rapidly followed by application to oligosaccharides by us and by other groups in the late 1990s. ${ }^{88-90}$ By use of dilute lyotropic liquid crystal media together with highresolution NMR techniques ${ }^{91}$ (Figure 11 ) RDCs, $d_{\mathrm{CH}}$ and $d_{\mathrm{HH}}$, can be determined $\left(J_{\mathrm{CH}}\right.$ and $J_{\mathrm{HH}}$ needed in the procedure are obtained under isotropic conditions). Subsequent analysis of a large number of RDCs in conjunction with a molecular model will give information on 3D structure and the degree of orientation of the molecule in the specific alignment medium. The specific advantage of the application of RDCs to conformational analysis is that relative orientations between sugar residues can be determined, in particular not only between adjacent residues as in most cases when ${ }^{1} \mathrm{H},{ }^{1} \mathrm{H}-\mathrm{NOEs}$ are used, but also for residues that are further apart. Applications of RDCs as an additional source of information was used in conformational analysis of a decasaccharide ${ }^{92}$ for which the preferred conformational space of the central $\beta$-( $1 \rightarrow 4)$-glycosidic linkage was investigated. Only a single transglycosidic ${ }^{1} \mathrm{H},{ }^{1} \mathrm{H}-\mathrm{NOE}$ was available and the experimentally determined distance of $2.14 \AA$ gave an estimate of $2.1-2.2 \AA$. From geometric considerations upon $\phi / \psi$ torsion angle rotations an accessible region can be defined (Figure 12). By utilization of experimentally determined $d_{\mathrm{CH}}$ and $d_{\mathrm{HH}}$ in the conformational analysis it was possible to identify a conformational sub-space which should be highly populated, i.e. $\phi=40 \pm 10^{\circ}$ and $\psi=30 \pm 10^{\circ}$, presented as a filled circle in Figure 12. In our studies on oligosaccharides that utilize RDCs as an important source of information, ${ }^{92,93,94}$ also ${ }^{1} \mathrm{H},{ }^{1} \mathrm{H}-\mathrm{NOEs}$ and trans-glycosidic ${ }^{3} J_{\mathrm{CH}}$ coupling constants are usually used as a source of experimental information.

Molecular simulations play an important part in the conformational and dynamics analysis of oligosaccharides that we carry out. Most often these are force field ${ }^{95}$ based molecular dynamics (MD) simulations ${ }^{96}$ with explicit water molecules as solvent but sometimes Langevin dynamics (LD) is used in which the solvent is modeled by frictional and random forces. In some cases oligosaccharides in 
other solvents or in mixed solvents have been investigated. ${ }^{97,98}$ The molecular mechanics force field used in these MD and LD simulations is of paramount importance. During the analysis of the conformational preferences for the trisaccharide which lead to the identification of the presence of anti$\phi$ conformers $^{58}$ (vide supra) it became evident that the CHARMM PARM22 force field used in the study needed improvements. Since we had experimental NMR data to rely on we set out to carry out and implement such an enhanced force field for carbohydrates. ${ }^{99}$ For the $\phi$ glycosidic torsion angle the axial and equatorial forms of 2-methoxytetrahydropyran (2MTHP) were chosen as model compounds for $\alpha$ - and $\beta$-glycopyranosides. The potential energies as a function of torsion angle were determined using density functional theory (DFT) calculations (Figure 13) and force field parameters were adjusted to fit these data. Since data from quantum mechanics calculations were available from literature data for the $\omega$ hydroxymethyl torsion rotation in glucopyranose and galactopyranose ${ }^{100}$ these were also included in the improved force field denoted PARM22/SU01. The force field was tested on a glucosecontaining trisaccharide glycoside for which trans-glycosidic proton-proton distances were available from experimental NMR data ${ }^{101}$ and the MD simulations showed excellent agreement to those observed from experiment. In addition, the population distribution for the $\omega$ torsion angles was indicated to be quite reasonable with transitions between the three staggered conformations (Figure 14). Subsequent MD simulations of other oligosaccharides have shown that the results from this modified force field agree well when compared to experimental NMR parameters such as ${ }^{3} J_{\mathrm{CH}}$ coupling constants or derived parameters such as effective proton-proton distances. This has also proven to be the case for $\beta$-D-GlcpNAc-( $1 \rightarrow 6)-\alpha$-D-Manp-OMe, a disaccharide related to an epitope on cancer cells, having three torsion angles $\phi, \psi$ and $\omega$ being part of the glycosidic linkage. The MD simulation data agreed to better than $0.1 \AA$ for the effective trans-glycosidic proton-proton distances, a limit that was also judged to be the experimental uncertainty from the $1 \mathrm{D}{ }^{1} \mathrm{H},{ }^{1} \mathrm{H}$-T-ROESY NMR experiments. The population distribution for the $\omega$ torsion angle differed by just a few percent between experiment and

simulation. ${ }^{81}$ Thus, the molecular mechanics force field based simulations describe conformational preferences and population distributions well and can in future studies be applied to large oligosaccharides of high complexity as well as to the study of polysaccharide conformation and dynamics.

\section{Oligosaccharide-protein interactions}

Many oligo- and polysaccharides interact with proteins and are part of important biochemical processes. The carbohydrate-protein binding process has been described as either an 'induced fit' or a 
'conformational selection'. ${ }^{102,103,104}$ Conceptually highly interesting is the fact that the $\mathrm{GM}_{1}$ pentasaccharide structure exhibits alternative binding modes, referred to as differential conformer selection, to two proteins, viz., galectin-1 and a cholera toxin. ${ }^{105}$ This finding highlights the fact that a certain primary structure may differ in three dimensions and result in discriminated responses to e.g. protein structural environments. Ligand flexibility is also of importance in the recognition of terminal $N$-acetyl-D-glucosamine residues by the protein Wheat Germ Agglutinin (WGA). Its interactions with the disaccharide $\beta$-D-GlcpNAc- $(1 \rightarrow 6)-\alpha-\mathrm{D}-\mathrm{Man} p-O M e$ (cf. above) was studied ${ }^{106}$ by ${ }^{1} \mathrm{H}$ STD NMR experiments ${ }^{107}$ which identifies the ligand protons in close contact with the protein. Thus, the binding epitope, i.e., the part of the molecule that is recognized, could be identified in this way. The conformation of the disaccharide when bound to the protein was identified from transfer-NOESY experiments $^{108}$ and out of six possible ligand conformations that were accessible based on molecular modeling of the ligand-protein interaction, one could be positively confirmed by $1 \mathrm{D}{ }^{1} \mathrm{H},{ }^{1} \mathrm{H}-\mathrm{NOESY}$ experiments. This binding mode is depicted in Figure 15.

Still more complex is the infection of several Salmonella strains by the P22 phage. The process is mediated by its tail-spike protein (TSP) which has both binding and hydrolyzing capabilities to the polysaccharide part of the LPS, the lipid of which is anchored in the outer membrane of the bacterium. The lysis products from the incubation of the TSP with the polysaccharide are octa- and dodecasaccharides corresponding to two and three repeating units. The results from STD and transferNOE experiments of the octasaccharide and the TSP indicated that the contact area was large between the ligand and a shallow groove in the protein. The conformation of the bound octasaccharide was similar to that in solution. Most interestingly, docking studies of the octasaccharide and the TSP using the Autodock program showed that one of the two most favorable energy interactions in the binding site was that at the hydrolysis site which previously was identified in a co-crystal between the octasaccharide and the TSP. ${ }^{109}$ The conformation of the docked octasaccharide was highly similar to that in the crystal structure. The other docked low energy structure had again a similar conformation, as analyzed by $\phi$ and $\psi$ torsion angles, but it was 'frame-shifted' by one repeating unit (Figure 16). ${ }^{110}$ Thus, the docking procedure using an oligosaccharide corresponding to two repeating units was able to enclose that having three repeating units in agreement with the major products formed by incubation experiments. These results underscore the predictive power of computational and molecular modeling approaches to the study of biomolecular interactions.

\section{Conclusions and outlook}


This short review has described the continuous and tightly coupled analysis chain, starting with structure determination of glycans, from analysis of the primary structure (components and sequence), followed by conformational and dynamics analysis to the study of interaction with proteins. The use of solution state NMR spectroscopy has been central in these studies, which also included organic synthesis to facilitate specific questions to be addressed, in conjunction with computational and molecular modeling techniques to interpret data and to predict results that subsequently can be tested by experiment. In the coming decade it is anticipated that the protocols for structure determination will be further refined employing e.g. ion mobility spectrometry-MS ${ }^{111}$ and that DFT calculations of $J$ coupling constants and chemical shifts, already used successfully in our laboratory, ${ }^{112}$ will aid these investigations. Computational approaches and other techniques, such as Raman Optical Activity, ${ }^{113}$ are anticipated to contribute to a thorough understanding of conformational behavior of oligosaccharides, and dynamics of polysaccharides. The screening of carbohydrate-protein interactions will be greatly

aided by the developments of glycan microarrays ${ }^{114}$ by which systems to be studied can be identified much more rapidly. In addition, unanticipated interactions may be revealed in this way. Furthermore, chemical approaches ${ }^{115}$ to defined and uniform glycoconjugates will be of considerable importance in order to unravel biological roles of glycans. ${ }^{116}$ The interaction studies by NMR spectroscopy using libraries of potential protein binders in conjunction with computational chemistry promise detailed descriptions at atomic resolution thereby giving information on the relationships between structure and function.

\section{Acknowledgements}

The work described herein from the author's laboratory was supported, inter alia, by grants from the Swedish Research Council (VR) and The Knut and Alice Wallenberg Foundation. Past and present students, post-doctoral fellows and colleagues are thanked for stimulating scientific collaborations.

\section{References}

1. Weintraub, A.; Widmalm, G.; Jansson, P.-E.; Jansson, M.; Hultenby, K.; Albert, M. J. Microb. Pathogen. 1994, 16, 235-241.

2. Kenne, L.; Lindberg, B.; Madden, J. K.; Lindberg, A. A. Carbohydr. Res. 1985, 139, $217-223$

3. Yang, J.; Nahm, M. H.; Bush, C. A.; Cisar, J. O. J. Biol. Chem. 2011, 286, 35813-35822.

4. Stenutz, R.; Weintraub, A.; Widmalm, G. FEMS Microbiol. Rev. 2006, 30, 382-403.

5. de Waard, P.; Koorevaar, A.; Kamerling, J. P.; Vliegenthart, J. F. G. J. Biol. Chem. 1991, 266, 4237-4243. 
6. Bennet, E. P.; Hassan, H.; Mandel, U.; Mirgorodskaya, E.; Roepstorff, P.; Burchell, J.; TaylorPapadimitriou, J.; Hollingsworth, M. A.; Merkx, G.; van Kessel, A. G.; Eiberg, H.; Steffensen, R. J. Biol. Chem. 1998, 273, 30472-30481.

7. Maes, E.; Bonachera, F.; Strecker, G.; Guerardel, Y. Carbohydr. Res. 2009, 344, 322-330.

8. $\quad$ Prescher, J. A.; Bertozzi, C. R. Cell 2006, 126, 851-854.

9. Jansson, P.-E.; Lindberg, B.; Widmalm, G.; Sandford, P. A. Carbohydr. Res. 1985, 139, 217-223.

10. Kocharova, N. A.; Knirel, Y. A.; Widmalm, G.; Jansson, P.-E.; Moran, A. P. Biochemistry 2000, 39, 4755-4760.

11. Rosén Klement, M. L.; Öjemyr, L.; Tagscherer, K.; Widmalm, G.; Wieslander, Å. Mol. Microbiol. 2007, 65, 1444-1457.

12. Vinogradov, E.; Bock, K. Angew. Chem. Int. Ed. 1999, 38, 671-674.

13. Bundle, D. R.; Lemieux, R. U. Meth. Carbohydr. Chem. 1976, 7, 79-86.

14. Daikoku, S.; Ako, T.; Kurimoto, A.; Kanie, O. J. Mass Spectrom. 2007, 42, 714-723.

15. Ravindranathan, S.; Feng, X.; Karlsson, T.; Widmalm, G.; Levitt, M. H. J. Am. Chem. Soc. 2000, 122, 1102-1115.

16. Naidoo, K. J.; Chen, J. Y.-J.; Jansson, J. L. M.; Widmalm, G.; Maliniak, A. J. Phys. Chem. B 2004, 108, 4236-4238.

17. Byrd, R. A.; Egan, W.; Summers, M. F.; Bax, A. Carbohydr. Res. 1987, 166, 47-58.

18. Bax, A.; Summers, M. F.; Egan, W.; Guirgis, N.; Schneerson, R.; Robbins, J. B.; Ørskov, F.; Ørskov, I.; Vann, W. F. Carbohydr. Res. 1988, 173, 53-64.

19. Kumar, A.; Ernst, R. R.; Wüthrich, K. Biochem. Biophys. Res. Commun. 1980, 95, 1-6.

20. Linnerborg, M.; Weintraub, A.; Widmalm, G. Eur. J. Biochem. 1999, 266, 460-466.

21. Jonsson, K. H. M.; Weintraub, A.; Widmalm, G. Carbohydr. Res. 2006, 341, 2986-2989.

22. Perepelov, A. V.; Liu, B.; Senchenkova, S. N.; Shashkov, A. S.; Feng, L.; Knirel, Y. A.; Wang, L. Carbohydr. Res. 2008, 343, 571-575.

23. Perepelov, A. V.; Weintraub, A.; Liu, B.; Senchenkova, S. N.; Shashkov, A. S.; Feng, L.; Wang, L.; Widmalm, G.; Knirel, Y. A. Carbohydr. Res. 2008, 343, 977-981.

24. Ali, T.; Weintraub, A.; Widmalm, G. Carbohydr. Res. 2006, 341, 1878-1883.

25. Larsson, E. A.; Urbina, F.; Yang, Z.; Weintraub, A.; Widmalm, G. Carbohydr. Res. 2004, 339, 1491-1496.

26. Urbina, F.; Nordmark, E.-L.; Yang, Z.; Weintraub, A.; Scheutz, F.; Widmalm, G. Carbohydr. Res. 2005, 340, 645-650.

27. Lycknert, K.; Widmalm, G. Biomacromolecules 2004, 5, 1015-1020. 
28. Olsson, U.; Weintraub, A.; Widmalm, G. Carbohydr. Res. 2008, 343, 805-809.

29. Jansson, P.-E.; Kenne, L.; Widmalm, G. Carbohydr. Res. 1987, 168, 67-77.

30. Jansson, P.-E.; Kenne, L.; Widmalm, G. Carbohydr. Res. 1989, 188, 169-191.

31. Jansson, P.-E.; Kenne, L.; Widmalm, G. J. Chem. Inf. Comput. Sci. 1991, 31, 508-516.

32. Jansson, P.-E.; Stenutz, R.; Widmalm, G. Carbohydr. Res. 2006, 341, 1003-1010.

33. Jansson, P.-E.; Kenne, L.; Widmalm, G. Carbohydr. Res. 1989, 193, 322-325.

34. Kupče, E.; Nishida, T.; Widmalm, G.; Freeman, R. Magn. Reson. Chem. 2005, 43, 791-794.

35. Linnerborg, M.; Weintraub, A.; Widmalm, G. Eur. J. Biochem. 1999, 266, 246-251.

36. Kjellberg, A.; Weintraub, A.; Widmalm, G. Biochemistry 1999, 38, 12205-12211.

37. Wang, W.; Sass, H. J.; Zähringer, U.; Grzesiek, S. Angew. Chem. Int. Ed. 2008, 47, 9870-9874.

38. Norris, S. E.; Landström, J.; Weintraub, A.; Bull, T. E.; Widmalm, G.; Freedberg, D. I. Biopolymers 2012, 97, 145-154.

39. Lundborg, M.; Fontana, C.; Widmalm, G. Biomacromolecules 2011, 12, 3851-3855.

40. Taha, H. A.; Richards, M. R.; Lowary, T. L. Chem. Rev. 2013, 113, xx-xx.

41. Freedberg, D. I. J. Am. Chem. Soc. 2002, 124, 2358-2362.

42. Ferro, D. R.; Provasoli, A.; Ragazzi, M.; Torri, G.; Casu, B.; Gatti, G.; Jacquinet, J.-C.; Sinä̈, P.; Petitou, M.; Choay, J. J. Am. Chem. Soc. 1986, 108, 6773-6778.

43. Sundararajan, P. R.; Rao, V. S. R. Tetrahedron 1968, 24, 289-295.

44. Jaud, S.; Tobias, D. J.; Brant, D. A. Biomacromolecules 2005, 6, 1239-1251.

45. Färnbäck, M.; Eriksson, L.; Widmalm, G. Acta Cryst. 2008, C64, o31-o32.

46. Eriksson, L.; Widmalm, G. Acta Cryst. 2005, E61, o860-o862.

47. Haasnoot, C. A. G.; de Leeuw, F. A. A. M.; Altona, C. Tetrahedron 1980, 36, 2783-2792.

48. Bock, K.; Duus, J. Ø. J. Carbohydr. Chem. 1994, 13, 513-543.

49. Köpper, S.; Brandenburg, A. J. Carbohydr. Chem. 1993, 12, 801-804.

50. Stenutz, R.; Carmichael, I.; Widmalm, G.; Serianni, A. S. J. Org. Chem. 2002, 67, 949-958.

51. Hassel, O; Ottar, B. Acta Chem. Scand. 1947, 1, 929-943

52. Thøgersen, H.; Lemieux, R. U.; Bock, K.; Meyer, B. Can. J. Chem. 1982, 60, $44-57$.

53. Kirby, A. J. The Anomeric Effect and Related Stereoelectronic Effects at Oxygen, SpringerVerlag, Berlin, 1983.

54. The Anomeric Effect and Associated Stereoelectronic Effects, ACS Symposium Series No. 539, Thatcher, G. R. J.; Ed., American Chemical Society, Washington, DC, 1993.

55. Takahashi, O.; Yamasaki, K.; Kohno, Y.; Ueda, K.; Suezawa, H.; Nishio, M. Carbohydr. Res. 2009, 344, 1225-1229. 
56. Jansson, P.-E.; Kenne, L.; Persson, K.; Widmalm, G. J. Chem. Soc., Perkin Trans. 1 1990, 591598.

57. Dabrowski, J.; Kožár, T.; Grosskurth, H.; Nifant’ev, N. E. J. Am. Chem. Soc. 1995, 117, 55345539.

58. Landersjö, C.; Stenutz, R.; Widmalm, G. J. Am. Chem. Soc. 1997, 119, 8695-8698.

59. Adeyeye, A.; Jansson, P.-E.; Kenne, L.; Widmalm, G. J. Chem. Soc., Perkin Trans. 2 1991, 963973.

60. Höög, C.; Landersjö, C.; Widmalm, G. Chem. Eur. J. 2001, 7, 3069-3077.

61. Massefski, W., Jr.; Redfield, A. G. J. Magn. Reson. 1988, 78, 150-155.

62. Dixon, A. M.; Widmalm, G.; Bull, T. E. J. Magn. Reson. 2000, 147, 266-272.

63. Widmalm, G.; Byrd R. A.; Egan, W. Carbohydr. Res. 1992, 229, 195-211.

64. Lycknert, K.; Helander, A.; Oscarson, S.; Kenne, L.; Widmalm, G. Carbohydr. Res. 2004, 339, 1331-1338.

65. Eklund, R.; Lycknert, K.; Söderman, P.; Widmalm, G. J. Phys. Chem. B 2005, 109, 19936-19945.

66. Landström, J.; Widmalm, G. Carbohydr. Res. 2010, 345, 330-333.

67. Söderman, P.; Widmalm, G. J. Org. Chem. 1999, 64, 4199-4200.

68. Söderman, P.; Widmalm, G. Carbohydr. Res. 1999, 316, 184-186.

69. Garegg, P. J. Acc. Chem. Res. 1992, 25, 575-580.

70. Kjellberg, A.; Widmalm, G. Biopolymers 1999, 50, 391-399.

71. Larsson, E. A.; Staaf, M.; Söderman, P.; Höög, C.; Widmalm, G. J. Phys. Chem. A 2004, 108, 3932-3937.

72. Rundlöf, T.; Venable, R. M.; Pastor, R. W.; Kowalewski, J.; Widmalm, G. J. Am. Chem. Soc. 1999, 121, 11847-11854.

73. Olsson, J. D. M.; Landström, J.; Rönnols, J.; Oscarson, S.; Widmalm, G. Org. Biomol. Chem. 2009, 7, 1612-1618.

74. Rundlöf, T.; Kjellberg, A.; Damberg, C.; Nishida, T.; Widmalm, G. Magn. Reson. Chem. 1998, 36, 839-847.

75. Kummerlöwe, G.; Luy, B. Ann. Report NMR Spectr. 2009, 68, 193-230.

76. Nishida, T.; Widmalm, G.; Sandor, P. Magn. Reson. Chem. 1995, 33, 596-599.

77. Meissner, A.; Sørensen, O. W. Magn. Reson. Chem. 2001, 39, 49-52.

78. Holme, T.; Rahman, M.; Jansson, P.-E.; Widmalm, G. Eur. J. Biochem. 1999, 265, 524-529.

79. Masoud, H.; Perry, M. B.; Brisson, J.-R.; Uhrin, D.; Richards, J. C. Can. J. Chem. 1994, 72, 14661477. 
80. Lycknert, K.; Edebrink, P.; Widmalm, G. Angew. Chem. Int. Ed. 2004, 43, 2288-2290.

81. Olsson, U.; Säwén, E.; Stenutz, R.; Widmalm, G. Chem. Eur. J. 2009, 15, 8886-8894.

82. Coxon, B. Adv. Carbohydr. Chem. Biochem. 2009, 62, 17-82.

83. Lipari, G.; Szabo, A. J. Am. Chem. Soc. 1982, 104, 4546-4559.

84. Bagley, S.; Kovacs, H.; Kowalewski, J.; Widmalm, G. Magn. Reson. Chem. 1992, 30, 733-739.

85. Mäler, L.; Lang, J.; Widmalm, G.; Kowalewski, J. Magn. Reson. Chem. 1995, 33, 541-548.

86. Widmalm, G. Relaxation and dynamics. NMR spectroscopy of glycoconjugates, Jiménez-Barbero, J.; Peters, T. Eds., Wiley-VCH, Weinheim, 2003, pp. 3-21.

87. Saupe, A. Angew. Chem. Int. Ed. 1968, 7, 97-112

88. Rundlöf, T.; Landersjö, C.; Lycknert, K.; Maliniak, A.; Widmalm, G. Magn. Reson. Chem. 1998, 36, 773-776.

89. Kiddle, G. R.; Homans, S. W. FEBS Lett. 1998, 436, 128-130.

90. Bolon, P. J.; Prestegard, J. H. J. Am. Chem. Soc. 1998, 120, 9366-9367.

91. Tian, F.; Al-Hashimi, H. M.; Craighead, J. L.; Prestegard, J. H. J. Am. Chem. Soc. 2001, 123, 485492.

92. Lycknert, K.; Maliniak, A.; Widmalm, G. J. Phys. Chem. A 2001, 105, 5119-5122.

93. Staaf, M.; Höög, C.; Maliniak, A.; Widmalm, G. Biochemistry 2001, 40, 3623-3628.

94. Stevensson, B.; Landersjö, C.; Widmalm, G.; Maliniak, A. J. Am. Chem. Soc. 2002, 124, 59465947.

95. Zhu, X.; Lopes, P. E. M.; MacKerell, A. D., Jr. WIREs Comput. Mol. Sci. 2012, 2, 167-185.

96. Becker, O. M.; Watanabe, M. Dynamics Methods. In Computational Biochemistry and Biophysics; Becker, O. M., MacKerell, A. D., Jr., Roux, B., Watanabe, M., Eds.; Marcel Dekker, New York, 2001; pp 39-67.

97. Vishnyakov, A.; Widmalm, G.; Laaksonen, A. Angew. Chem. Int. Ed. 2000, 39, 140-142.

98. Vishnyakov, A.; Laaksonen, A.; Widmalm, G. J. Mol. Graphics Modell. 2001, 19, 338-342, 396397.

99. Eklund, R.; Widmalm, G. Carbohydr. Res. 2003, 338, 393-398.

100. Kirschner, K. N.; Woods, R. J. Proc. Nat. Acad. Sci. 2001, 98, 10541-10545.

101. Rundlöf, T.; Eriksson, L.; Widmalm, G. Chem. Eur. J. 2001, 7, 1750-1758.

102. Bucher, D.; Grant, B. J.; McCammon, J. A. Biochemistry 2011, 50, 10530-10539.

103. Bucher, D.; Grant, B. J.; Markwick, P. R.; McCammon, J. A. PLoS Comput. Biol. 2011, 7, e1002034. 
104. Nieto, L.; Canales, Á.; Giménez-Gallego, G.; Nieto, P. M.; Jiménez-Barbero, J. Chem. Eur. J. 2011, 17, 11204-11209.

105. Siebert, H.-C.; André, S.; Lu, S.-Y.; Frank, M.; Kaltner, H.; van Kuik, J. A.; Korchagina, E. Y.; Bovin, N.; Tajkhorshid, E.; Kaptein, R.; Vliegenthart, J. F. G.; von der Lieth, C.-W.; JiménezBarbero, J.; Kopitz, J.; Gabius, H.-J. Biochemistry 2003, 42, 14762-14773.

106. Lycknert, K.; Edblad, M.; Imberty, A.; Widmalm, G. Biochemistry 2004, 43, 9647-9654.

107. Mayer, M.; Meyer, B. J. Am. Chem. Soc. 2001, 123, 6108-6117.

108. Clore, G. M.; Gronenborn, A. M. J. Magn. Reson. 1982, 48, 402-417.

109. Steinbacher, S.; Miller, S.; Baxa, U.; Budisa, N.; Weintraub, A.; Seckler, R.; Huber, R. J. Mol. Biol. 1997, 267, 865-880.

110. Landström, J.; Nordmark, E.-L.; Eklund, R.; Weintraub, A.; Seckler, R.; Widmalm, G. Glycoconjugate J. 2008, 25, 137-143.

111. Smith, D. P.; Knapman, T. W.; Campuzano, I.; Malham, R. W.; Berryman, J. T.; Radford, S. E.; Ashcroft, A. E. Eur. J. Mass Spectrom. 2009, 15, 113-130.

112. Roščić, M.; Eklund, R.; Nordmark, E.-L.; Horvat, Š.; Widmalm, G. Eur. J. Org. Chem. 2004, 4641-4647.

113. Zhu, F.; Isaacs, N. W.; Hecht, L.; Tranter, G. E.; Barron, L. D. Chirality 2006, 18, 103-115.

114. Liang, P.-H.; Wang, S.-K.; Wong, C.-H. J. Am. Chem. Soc. 2007, 129, 11177-11184.

115. Agard, N. J.; Bertozzi, C. R. Acc. Chem. Res. 2009, 42, 788-797.

116. Tsuboi, S. Biol. Pharm. Bull. 2012, 35, 1633-1636. 


\section{Figures}

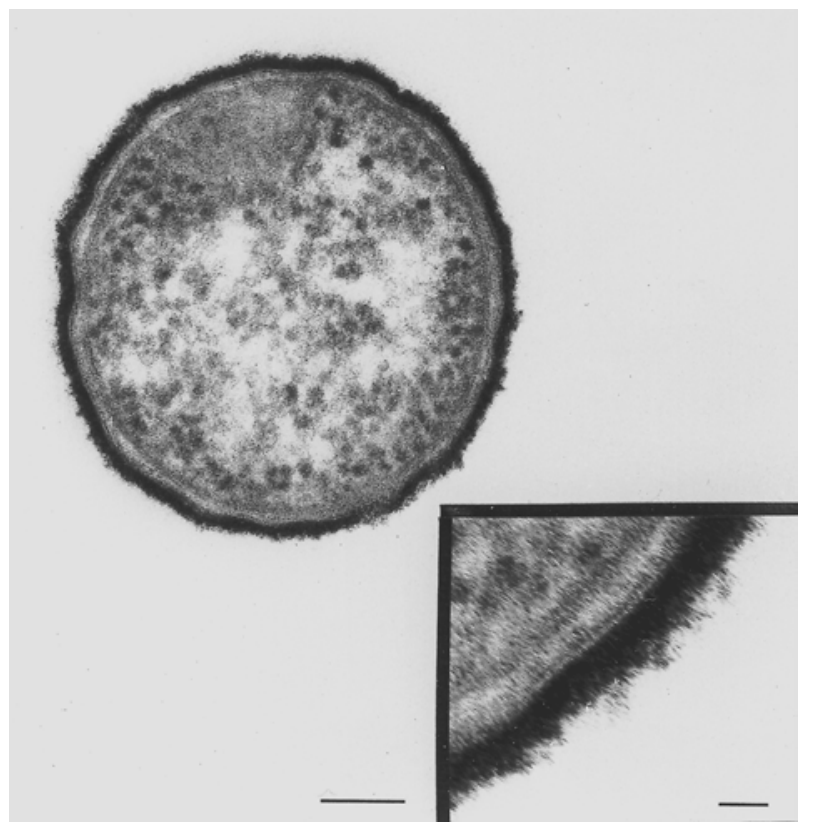

Figure 1. Electron microscopy picture of the bacterial cell of Vibrio cholerae O139, strain AI-1838, demonstrating the presence of a capsular polysaccharide (bar = $100 \mathrm{~nm}$; insert bar = $20 \mathrm{~nm}$ ).

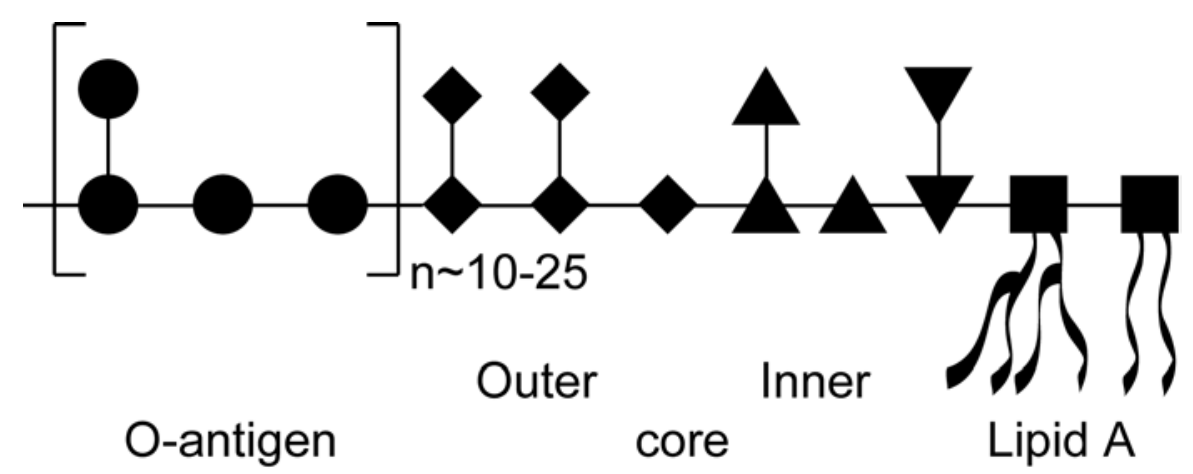

Figure 2. Schematic structure of an enterobacterial LPS molecule. The lipids are depicted by curved lines and the sugar residues are given by: GlcN $(\boldsymbol{\nabla})$, $\operatorname{Kdo}(\boldsymbol{\nabla})$, heptose $(\boldsymbol{\Delta})$, hexose $(\boldsymbol{\nabla})$, and O-antigen components (๑). 


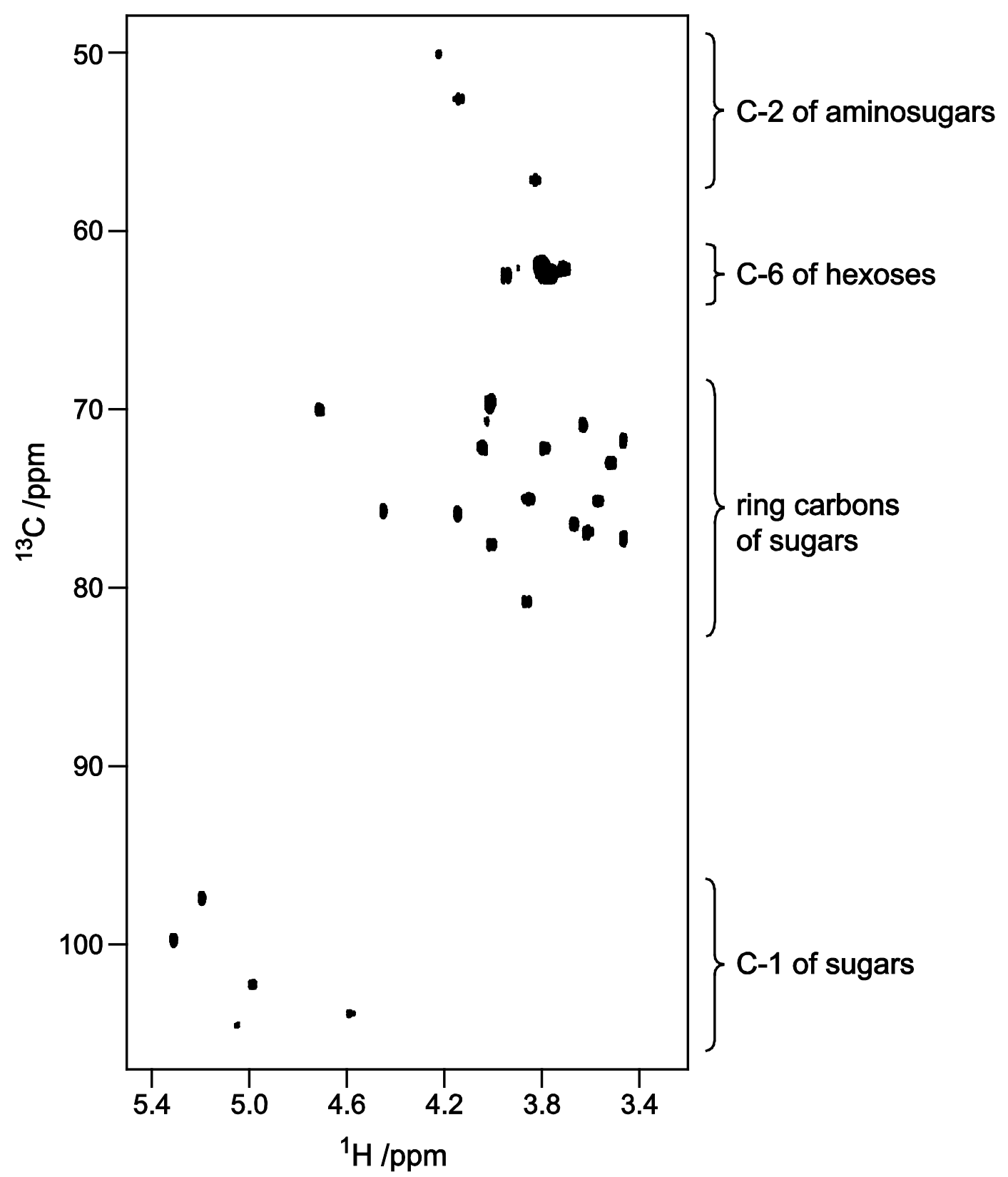

Figure 3. The ${ }^{1} \mathrm{H},{ }^{13} \mathrm{C}-\mathrm{HSQC}$ NMR spectrum of the LPS-OH from E. coli O112ab. 


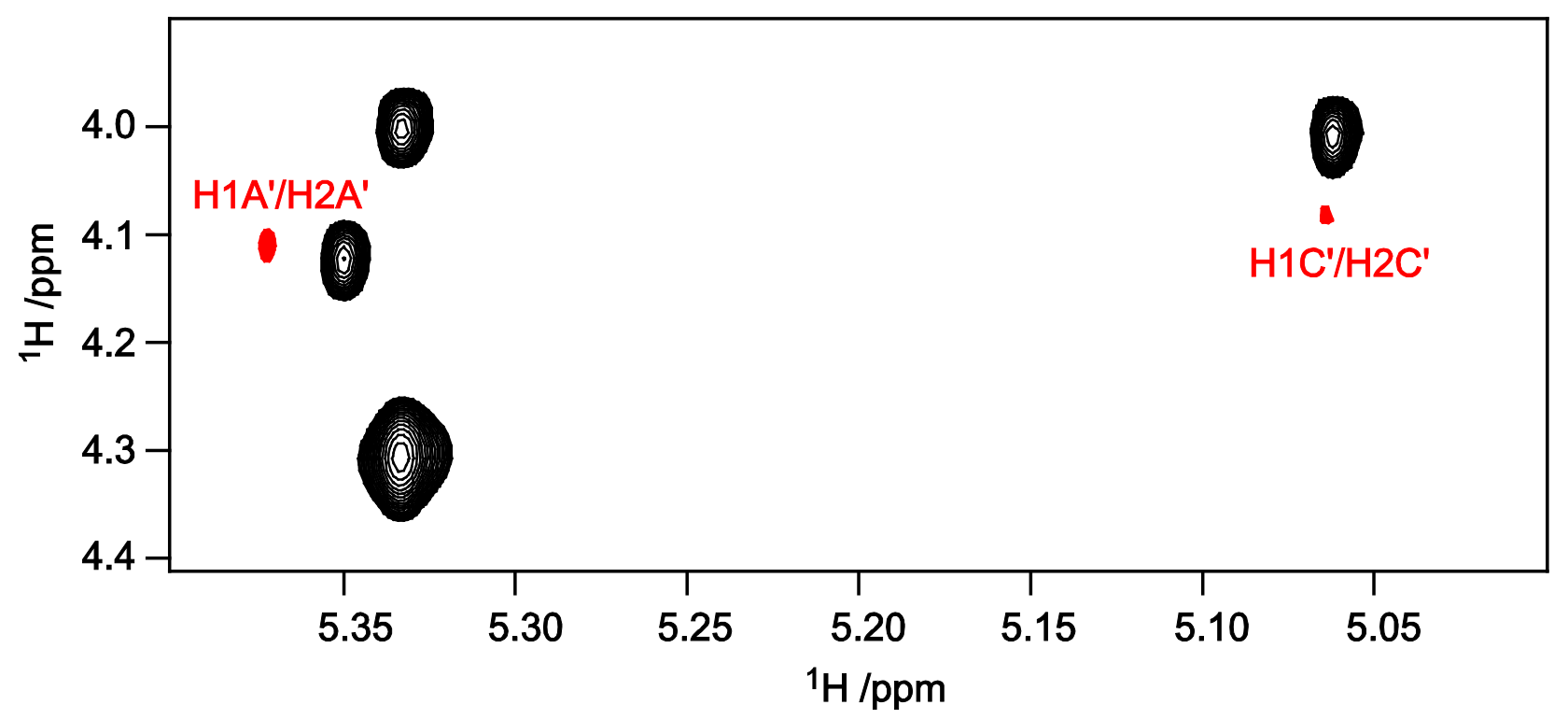

Figure 4. Part of the ${ }^{1} \mathrm{H},{ }^{1} \mathrm{H}$-TOCSY NMR spectrum (mixing time $30 \mathrm{~ms}$ ) of the O-antigen PS from $E$. coli O176. The minor H1/H2 cross-peaks (red color) arise from the terminal residue in the polymer, denoted C', and the penultimate residue, denoted A', respectively. 

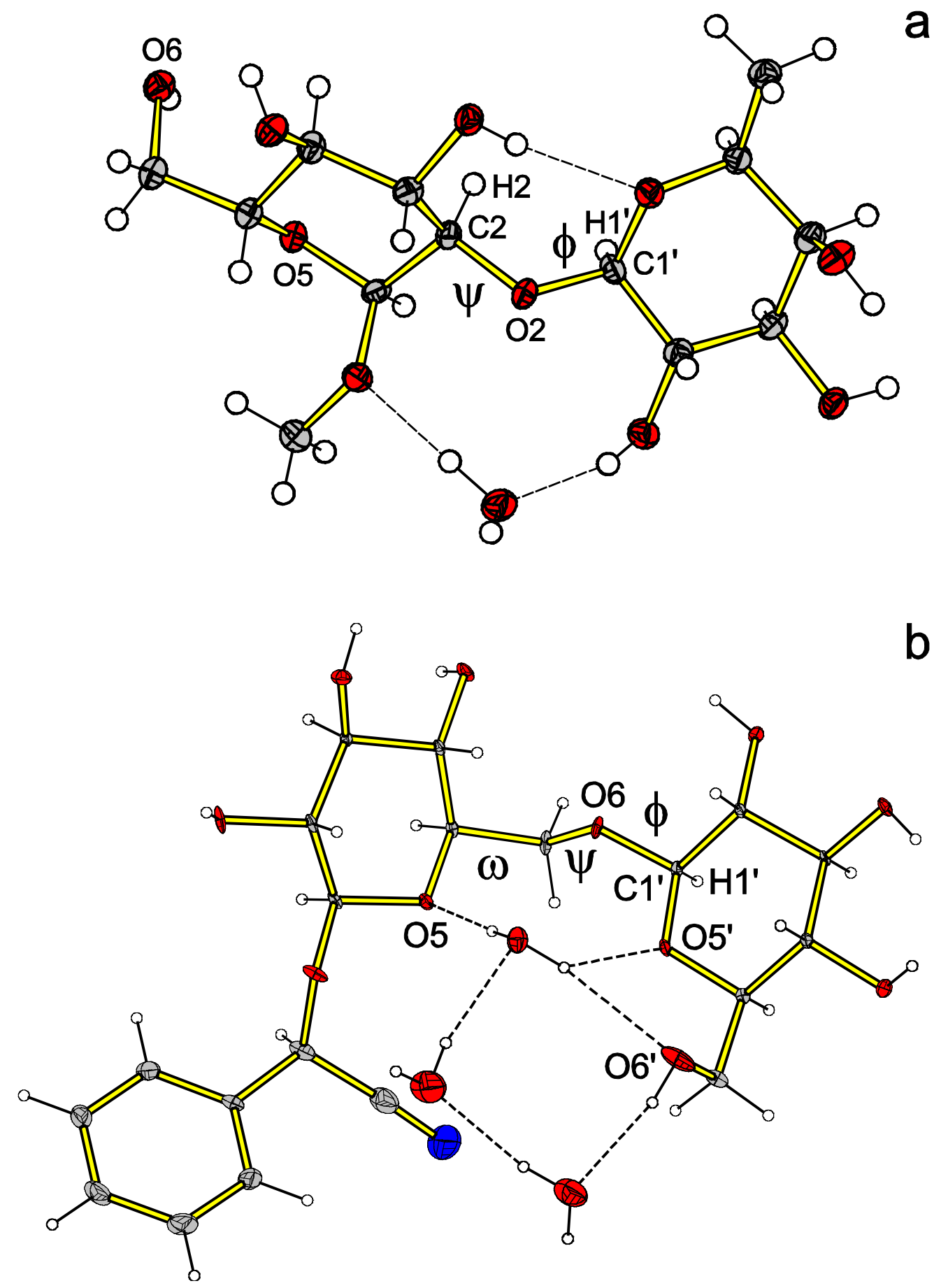

Figure 5. Crystal structures of $\beta$-L-Fucp-(1 $\rightarrow 2)$ - $\alpha$-D-Glcp-OMe (a) and (R)-1-cyano-1-(phenylmethyl)$\beta$-D-glucopyranosyl-( $1 \rightarrow 6)-\beta$-D-glucopyranoside (b). The glycosidic torsion angles $\phi$ and $\psi$ are for the $(1 \rightarrow 2)$-linked disaccharide defined by H1'-C1'-O2-C2 and C1'-O2-C2-H2, respectively, where the atoms of the glucosyl residue are non-primed. In the $(1 \rightarrow 6)$-linked disaccharide the $\phi$, $\psi$ and $\omega$ torsion angles are defined by H1'-C1'-O6-C6, C1'-O6-C6-C5, and O6-C6-C5-O5, respectively. 

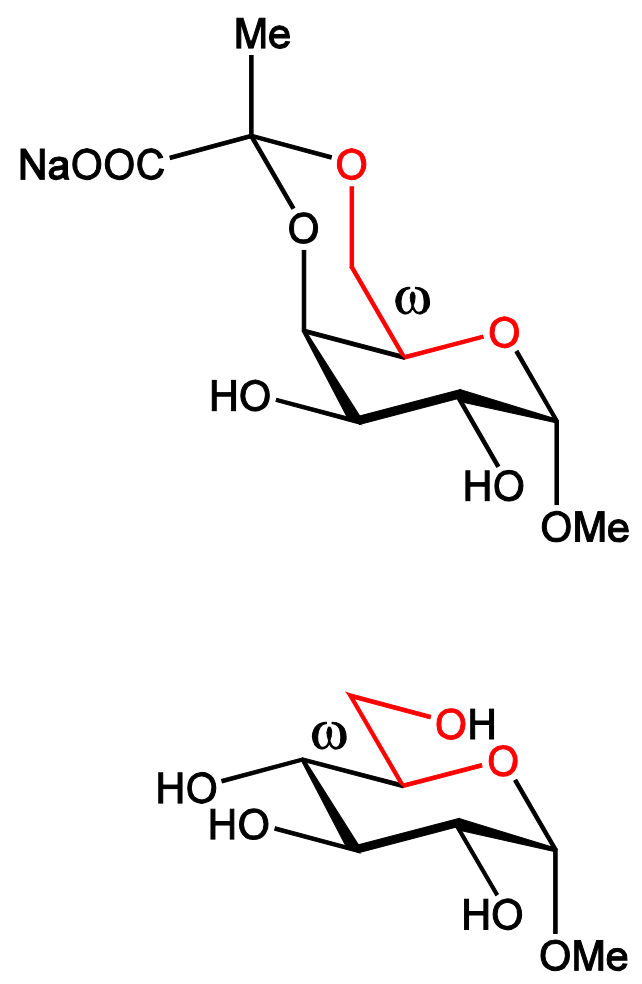
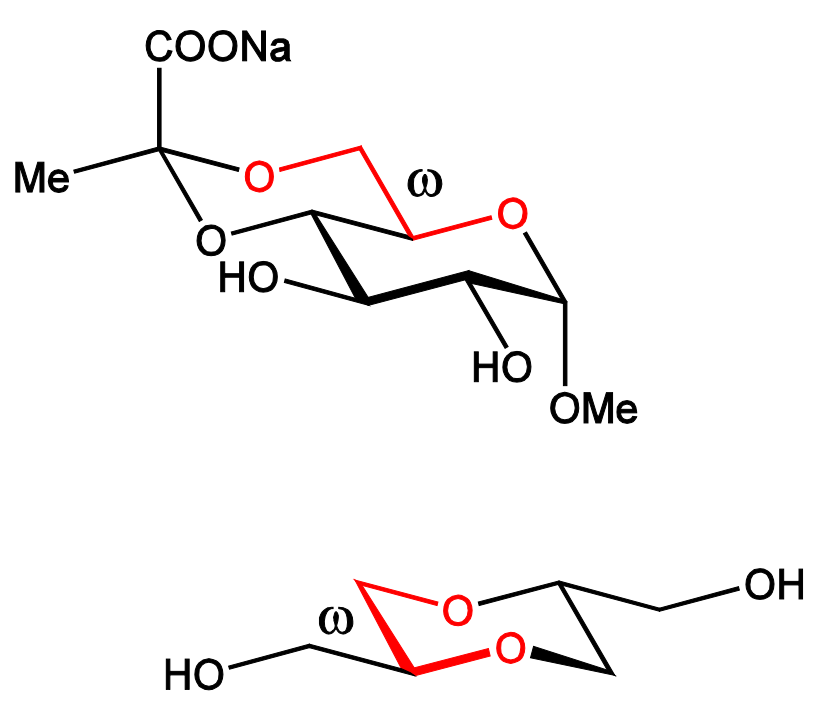

Figure 6. Models for the gauche-gauche ( $g g$ ) conformation of the O5-C5-C6-O6 torsion angle with $\omega=-60^{\circ}$ (upper left) and trans-gauche ( $\mathrm{tg}$ ) conformation with $\omega=180^{\circ}$ (upper right). However, for the gauche-trans ( $g t$ ) with $\omega=60^{\circ}$ (lower left) an equivalent rigid model is not available but trans-2,5bis(hydroxymethyl)-1,4-dioxane was identified to fulfill the conformational preferences adequately for a gt model (lower right). 

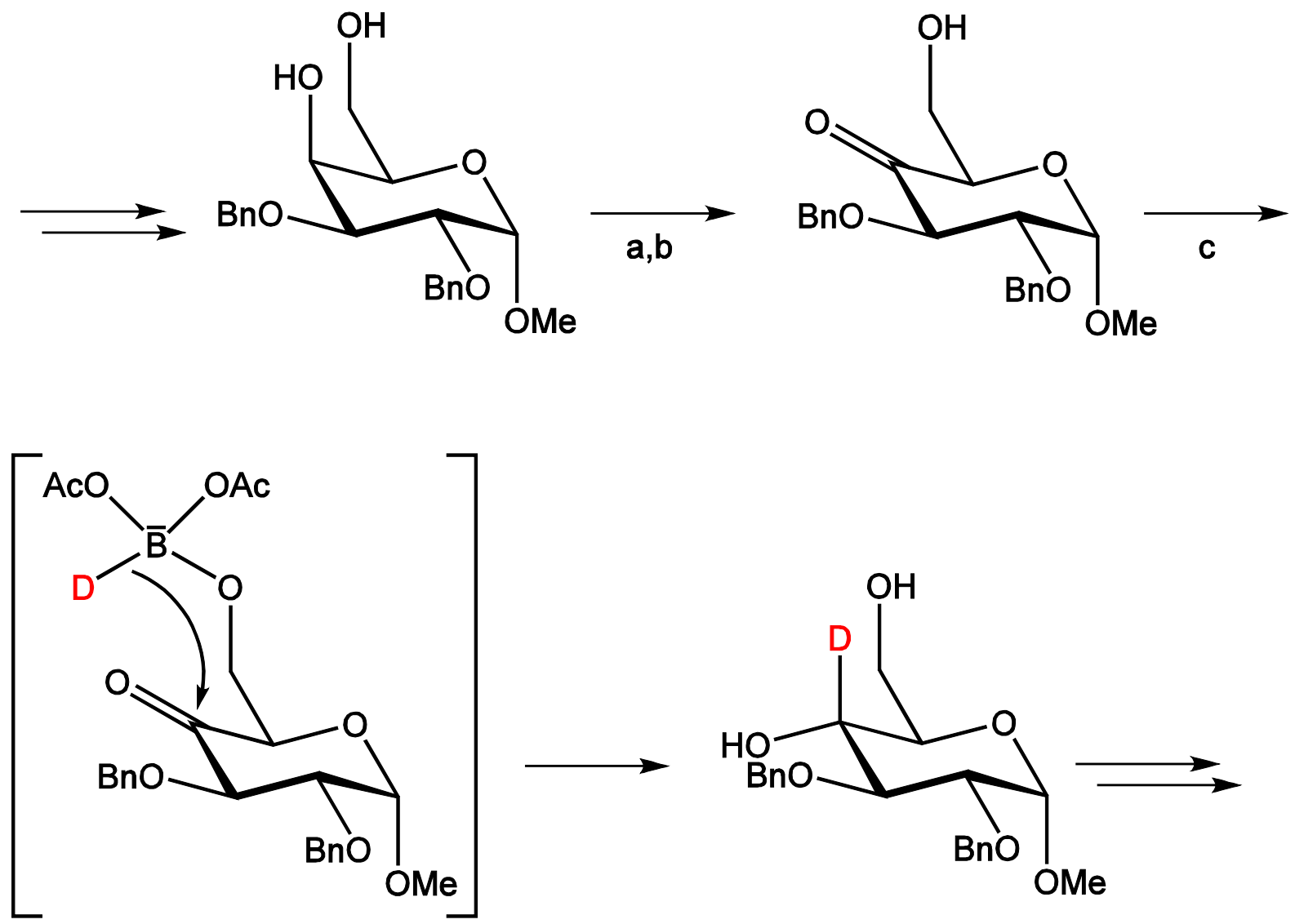

Figure 7. Part of the synthesis scheme for the synthesis of the site-specifically ${ }^{2} \mathrm{H}$-labeled methyl cellobioside; (a) $\mathrm{Bu}_{2} \mathrm{SnO}$, toluene, $3 \mathrm{~h}$, reflux; (b) 1,3-dibromo-5,5-dimethylhydantoin, 15 min, $25{ }^{\circ} \mathrm{C}$; (c) $\mathrm{NaB}^{2} \mathrm{H}(\mathrm{OAc})_{3}, 1 \mathrm{~h}, 0{ }^{\circ} \mathrm{C}$. 


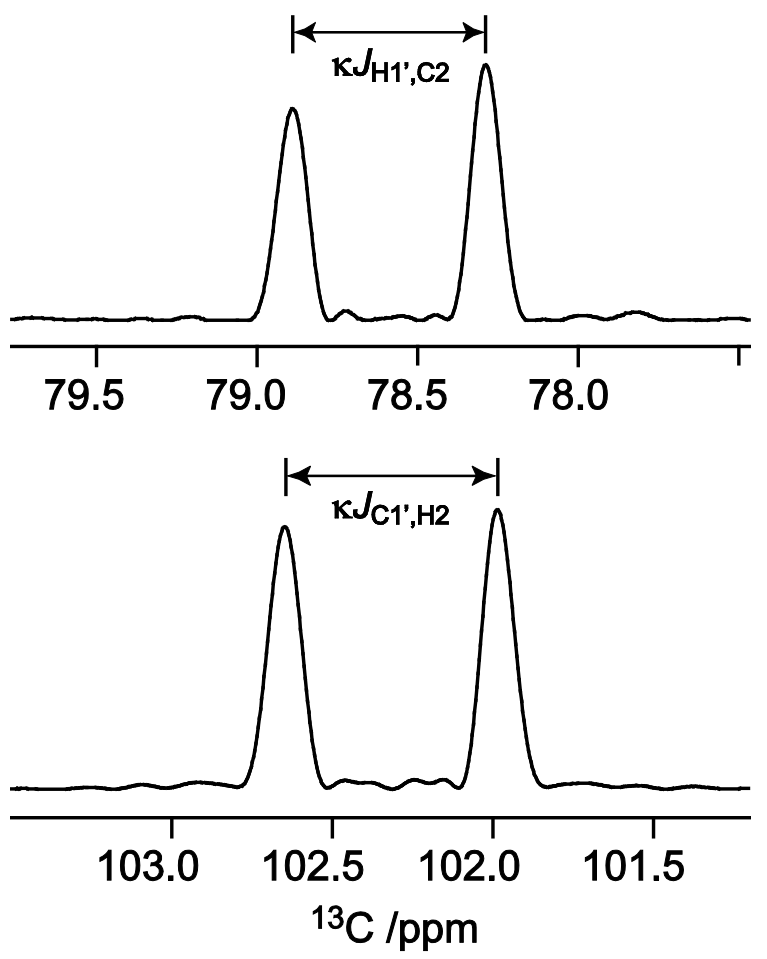

Figure 8. $\mathrm{F}_{1}$ section from the J-HMBC spectrum of $\alpha$-L-Rhap-(1 $\left.\rightarrow 2\right)-\alpha-\mathrm{L}-\mathrm{Rh}$-H-OMe for determination of the experimental (a) $J_{\mathrm{H} 1}$, C2 value related to $\phi$ and (b) $J_{\mathrm{C} 1{ }^{\prime}, \mathrm{H} 2}$ value related to $\psi$. A scaling factor $\kappa=$ 25.8 was used which results in an apparent splitting of the doublet by $\kappa J$ relative to the ${ }^{13} \mathrm{C}$ chemical shift. 


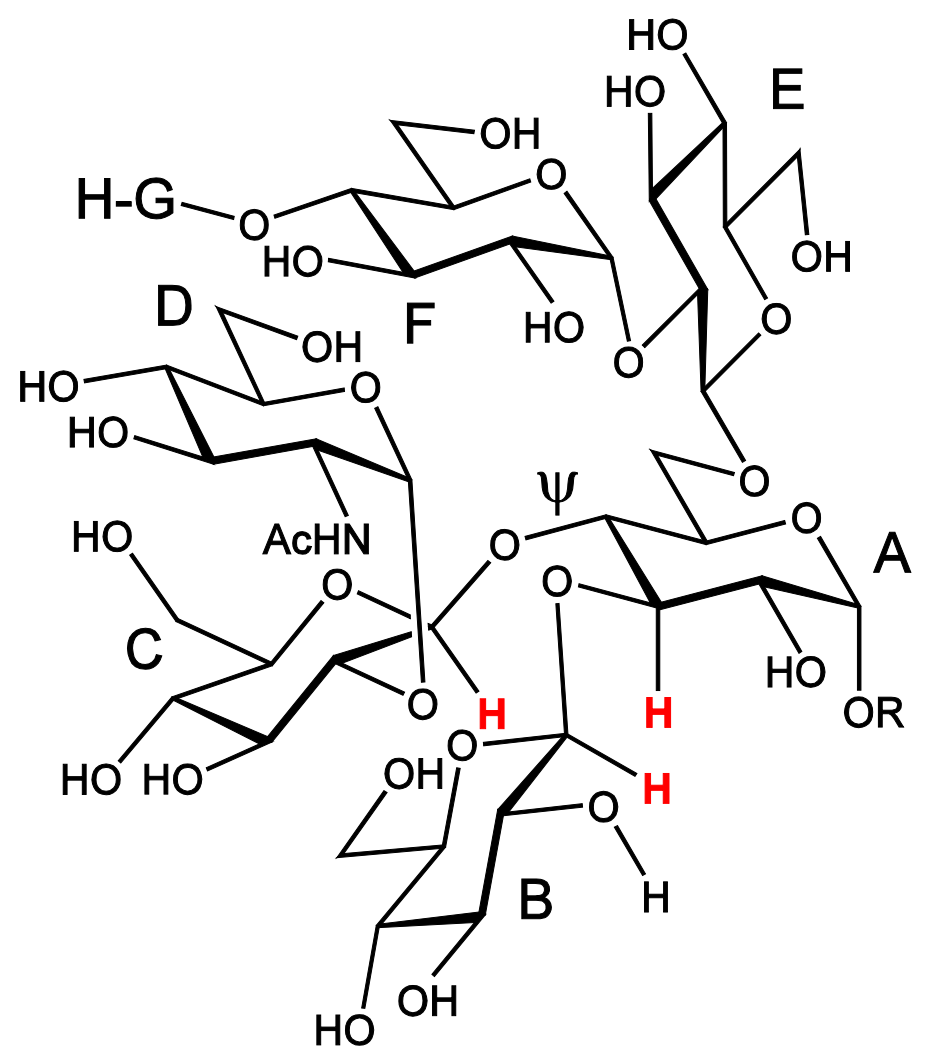

Figure 9. Structure of the oligosaccharide part determining serotype A of the LPS from M. catarrhalis. In the native material the $\mathrm{R}$ group represents lipid $\mathrm{A}$ and Kdo residues whereas in the synthetic oligosaccharides $\mathrm{R}$ equals a 2-(4-trifluoroacetamidophenyl)-ethyl group. The sugar residues are denoted by letters A through $\mathbf{H}$. Protons for which key NOEs are present are indicated by red color. 


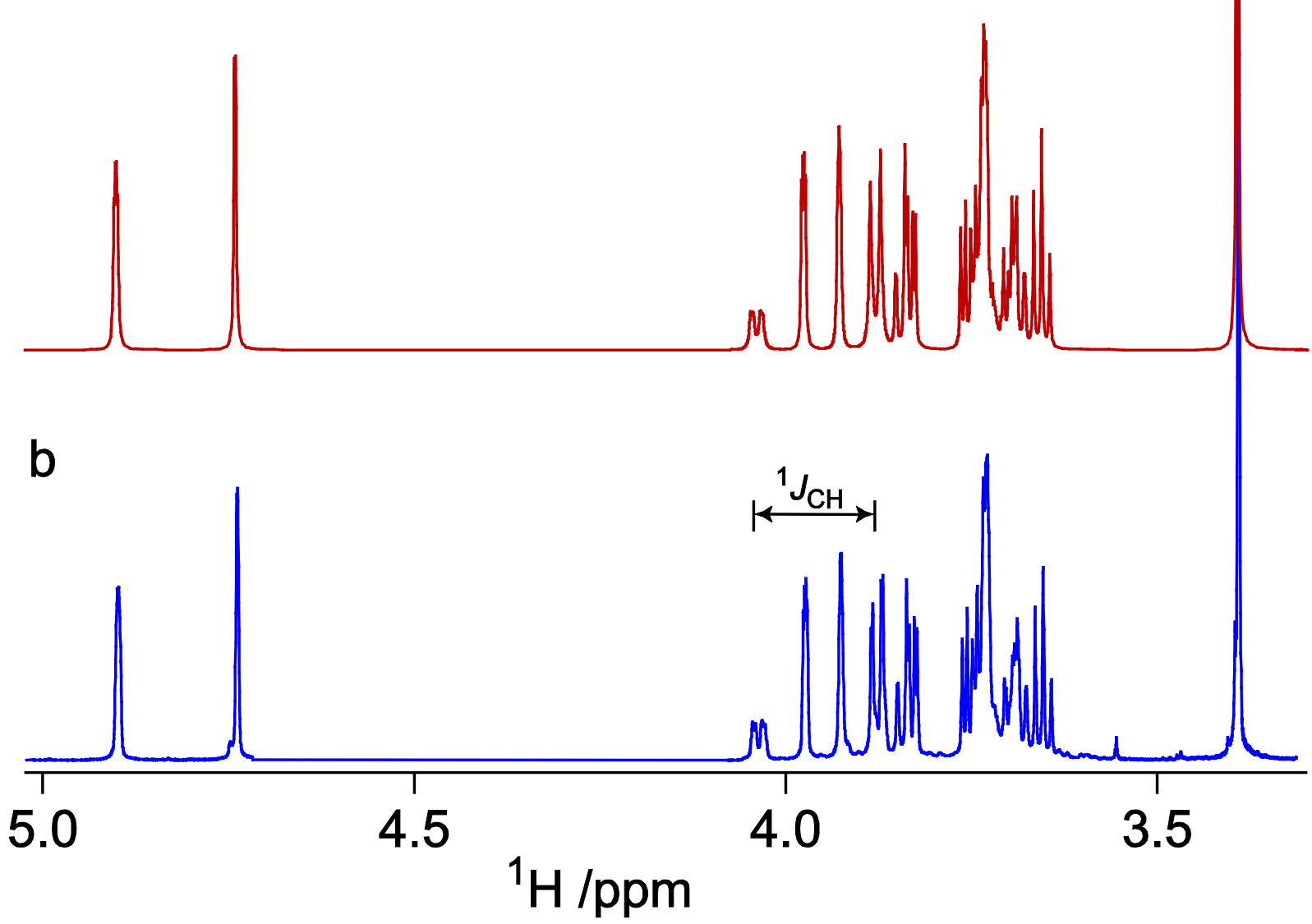

Figure 10. ${ }^{1} \mathrm{H}$ NMR spectra at $900 \mathrm{MHz}$ of $\alpha$-D-Manp- $(1 \rightarrow 6)-\alpha-\mathrm{D}-\left[6-{ }^{13} \mathrm{C}\right] \mathrm{Man} p-\mathrm{OMe}$ (a) by totallineshape analysis using the PERCH NMR simulation software and (b) from the corresponding experiment (HDO peak removed). From the total-lineshape analysis ${ }^{n} J_{\mathrm{HH}}$ and ${ }^{\mathrm{n}} J_{\mathrm{CH}}$ coupling constants can be extracted that subsequently can be used in conformational analysis. The H6 pro-R resonance at $3.96 \mathrm{ppm}$ is split by the $146 \mathrm{~Hz}^{1} J_{\mathrm{C} 6 \text {,H6pro- } R}$ coupling, indicated in the experimental spectrum. 

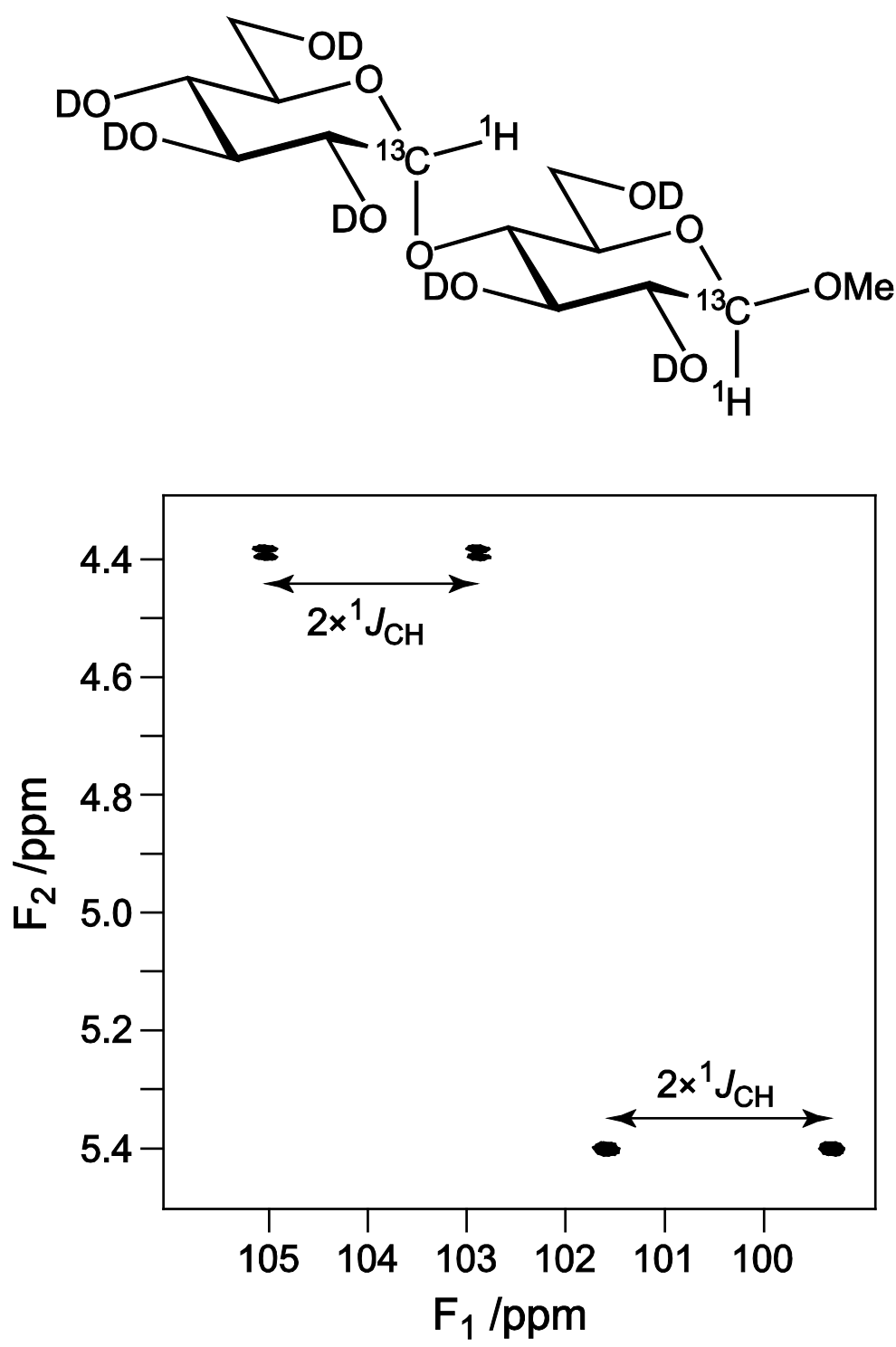

Figure 11. Schematic of methyl $\beta$-maltoside with anomeric ${ }^{13} \mathrm{C}$ and ${ }^{1} \mathrm{H}$ atoms highlighted and the anomeric region of a ${ }^{1} \mathrm{H},{ }^{13} \mathrm{C}-\mathrm{CT}$-CE-HSQC NMR spectrum of the disaccharide in $\mathrm{D}_{2} \mathrm{O}$ showing the doubled (coupling enhanced) ${ }^{13} \mathrm{C},{ }^{1} \mathrm{H}$-splittings along the $\mathrm{F}_{1}$ axis. 


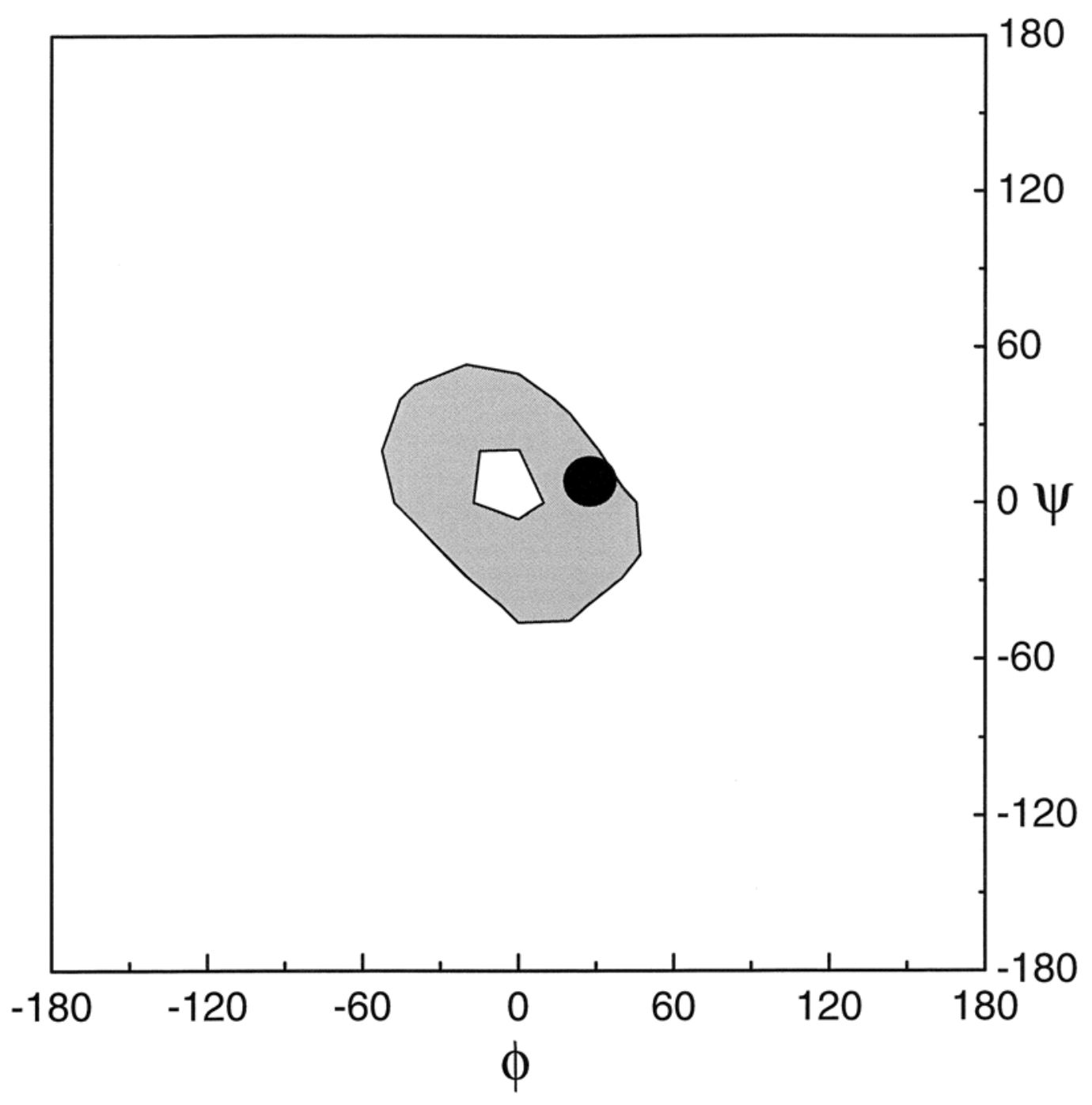

Figure 12. Ramachandran map, generated in $10^{\circ}$ increments using the CHARMm program, of the conformational space for the central $\beta$-(1 $\rightarrow 4)$-glycosidic linkage in a decasaccharide. The region consistent with ${ }^{1} \mathrm{H},{ }^{1} \mathrm{H}$ NOE data is shown in gray, and the conformation consistent with the dipolar coupling data is indicated by the black filled circle. Reproduced with permission from (Lycknert, K.; Maliniak, A.; Widmalm, G. J. Phys. Chem. A 2001, 105, 5119-5122). Copyright (2001) American Chemical Society. 

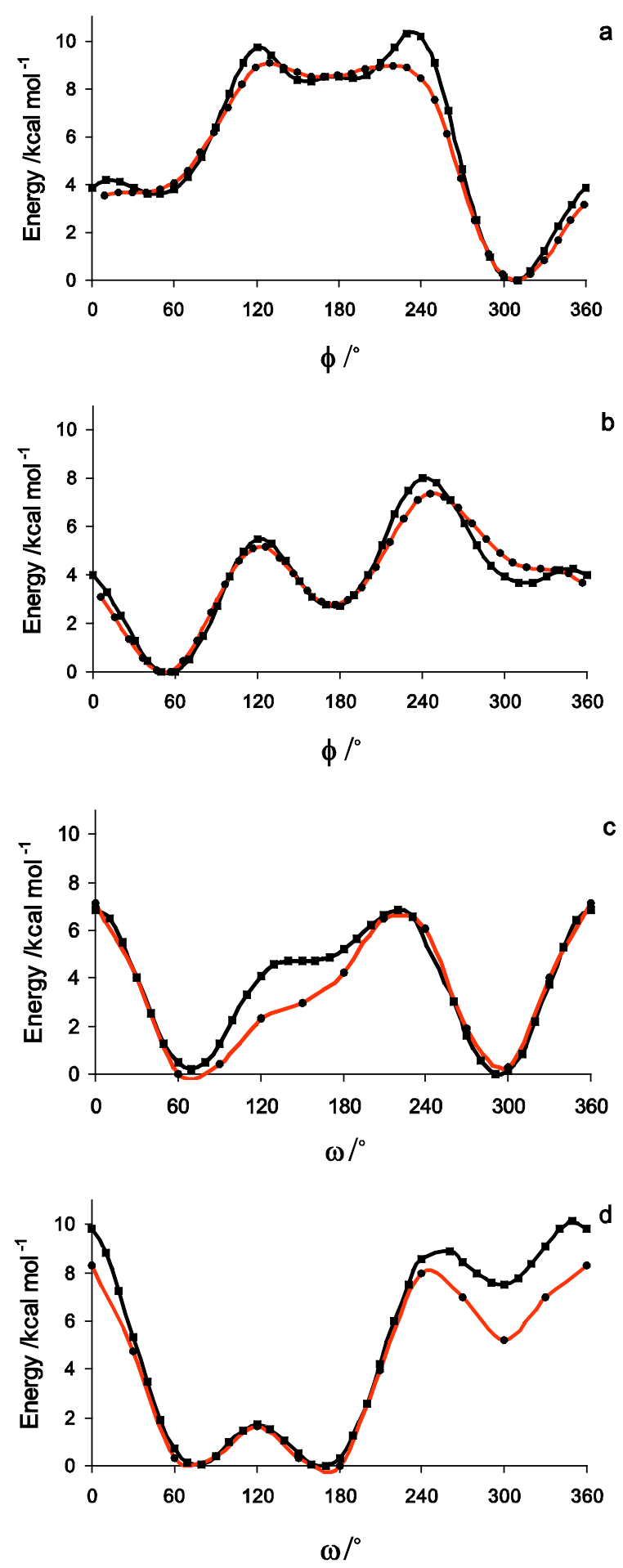

Figure 13. Potential energy curves of $\phi$ in (a) axial 2MTHP, (b) equatorial 2MTHP, and $\omega$ in (c) $\alpha$-DGlcp-OMe and (d) $\alpha$-D-Galp-OMe calculated by DFT or quantum mechanics (๑) and the derived PARM22/SU01 molecular mechanics (ם) methods. Reproduced with permission from (Eklund, R.; Widmalm, G. Carbohydr. Res. 2003, 338, 393-398). Copyright (2003) Elsevier. 


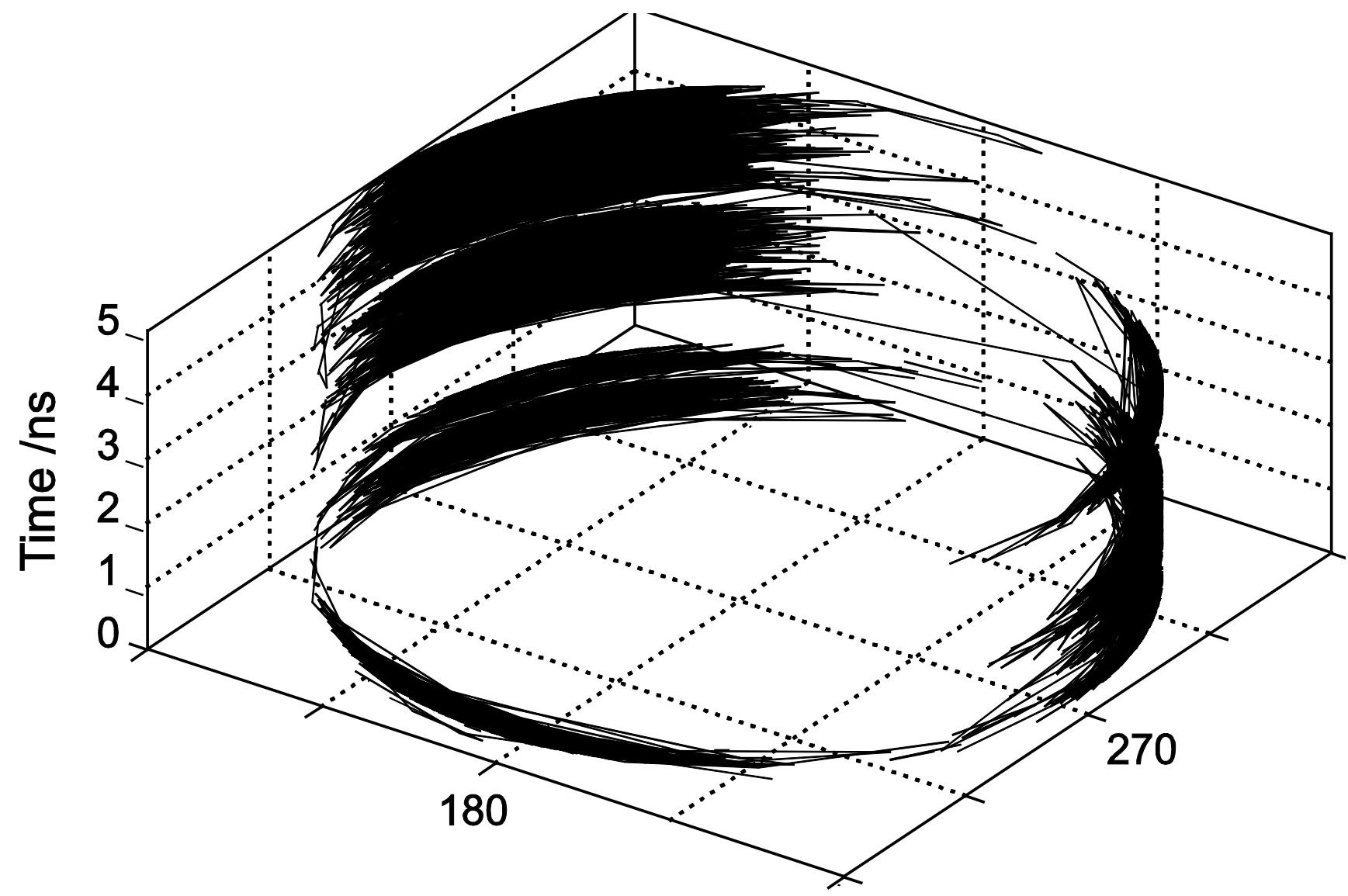

$\omega / /^{\circ}$

Figure 14. MD trajectory of the $\omega$ torsion angle of the $\alpha$-D-Glcp residue in $\beta$-D-Glcp-( $1 \rightarrow 2)[\beta$-D-Glcp$(1 \rightarrow 3)]-\alpha-D-G l c p-O M e$. Reproduced with permission from (Eklund, R.; Widmalm, G. Carbohydr. Res. 2003, 338, 393-398). Copyright (2003) Elsevier. 

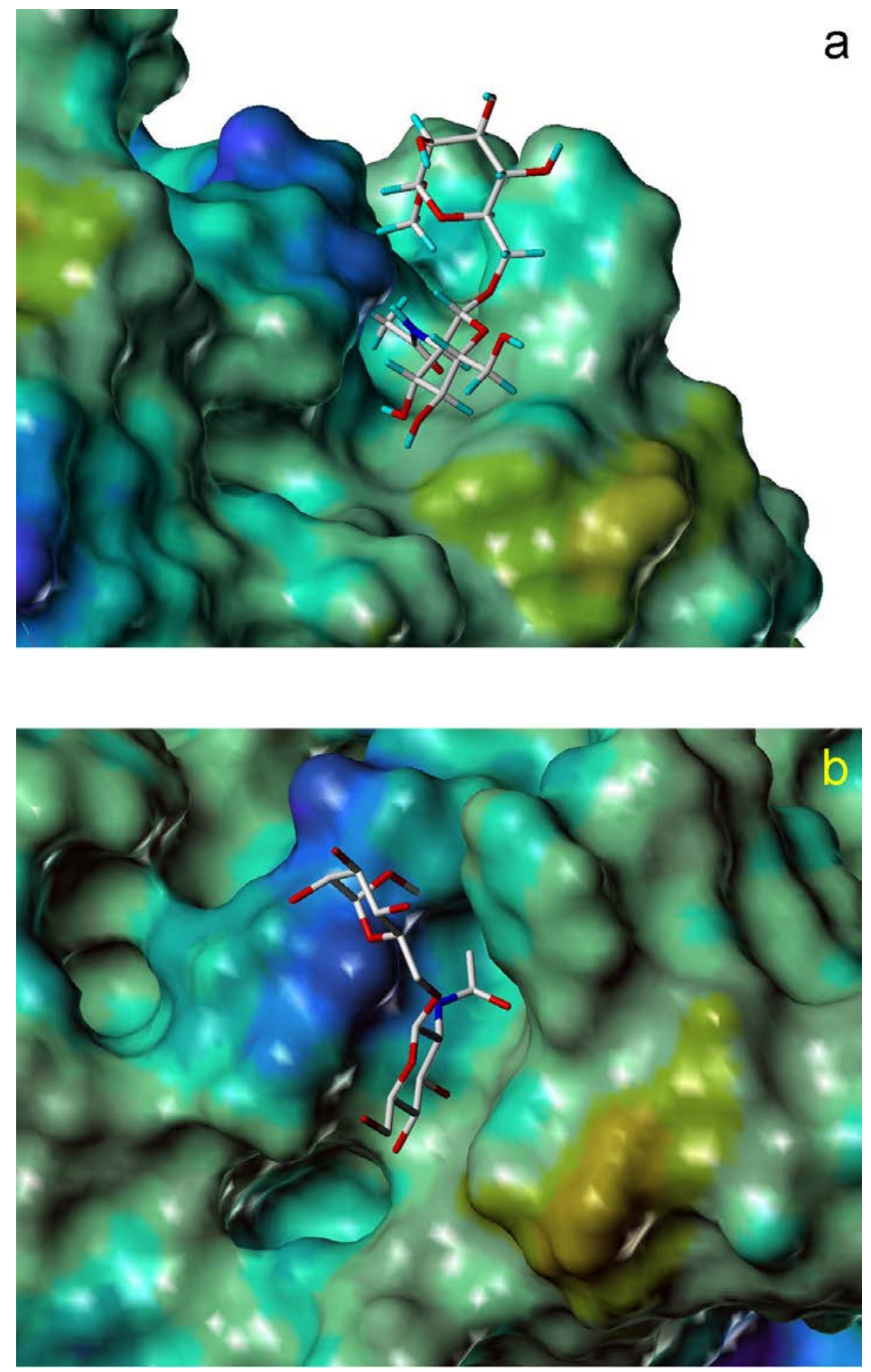

Figure 15. Molecular model $\beta$-D-GlcpNAc-(1 $\rightarrow 6)-\alpha-\mathrm{D}-\mathrm{Manp}$-OMe in a primary binding site of WGA, where the protein is color coded according to the electrostatic potential. The conformation of $\omega$ in the disaccharide is $g t$ and $\psi$ is around $-100^{\circ}$; (a) side-view and (b) top-view with omission of the hydrogen atoms. Reproduced with permission from (Lycknert, K.; Edblad, M.; Imberty, A.; Widmalm, G. Biochemistry 2004, 43, 9647-9654). Copyright (2004) American Chemical Society. 


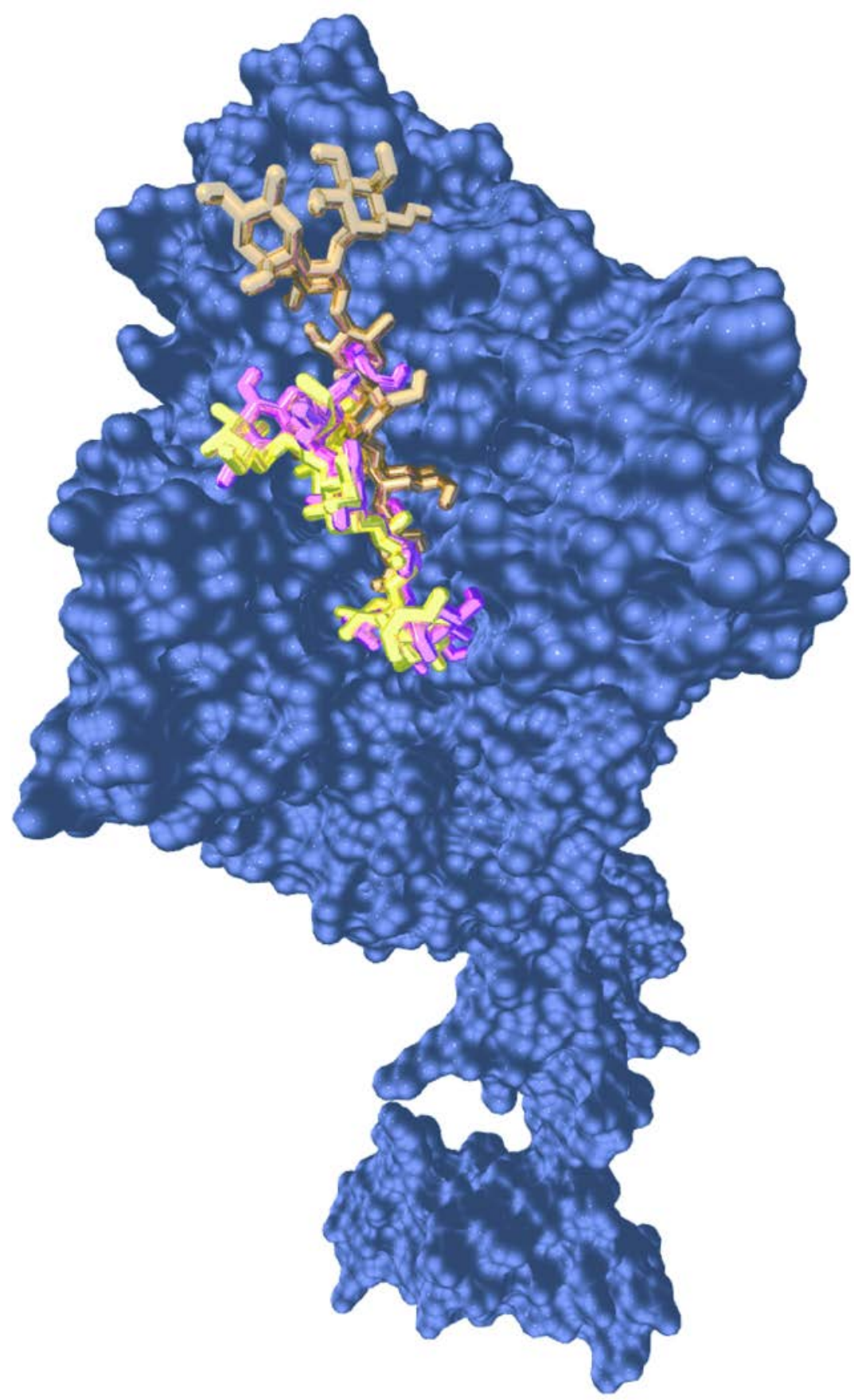

Figure 16. Molecular model of the octasaccharide-TSP complex with the lowest intermolecular interaction energy observed upon docking (brown) in which the ligand is shifted away from the active hydrolysis site and the next to lowest energy (yellow) which is similar to the crystal structure of the complex (purple). Only one subunit of the trimeric TSP is shown. Reproduced with permission from (Landström, J.; Nordmark, E.-L.; Eklund, R.; Weintraub, A.; Seckler, R.; Widmalm, G. Glycoconjugate J. 2008, 25, 137-143). Copyright (2008) Springer. 